\title{
Pharmacological Treatment of Fibrosis: a Systematic Review of Clinical Trials
}

\author{
Alessandro Siani ${ }^{1}$ (B) \\ Accepted: 16 April 2020 / Published online: 4 May 2020 \\ (C) The Author(s) 2020
}

\begin{abstract}
The term "fibrosis" refers to a spectrum of connective tissue disorders characterized by the excessive accumulation of extracellular matrix leading to organ dysfunction and, ultimately, failure. Fibrosis affects millions of patients worldwide and often manifests itself as a late-stage pathological condition associated with poor prognostic outcome. Although the aetiology and clinical course vary widely depending on the affected organ, fibrotic degeneration of different tissues is underpinned by similar molecular and cellular mechanisms, most notably the persistence and dysregulated activity of myofibroblasts. A systematic search of clinical trials was conducted using PubMed and Cochrane to qualitatively evaluate the effectiveness of different therapeutic approaches to the pharmacological targeting of myofibroblasts in patients affected by fibrotic disorders. The systematic search and screening returned 54 eligible clinical trials, 38 of which reported an improvement of the patients' symptoms following treatment. The majority of the eligible articles focused on fibrotic degeneration of the respiratory system, skin, liver, and kidneys. The evaluation of clinical data unearthed commonalities between strategies that successfully ameliorated symptoms in patients affected by the same fibrotic disorder. However, none of the treatments evaluated in this study could improve symptoms across a range of fibrotic pathologies. These results indicate that, although no "one size fits all" treatment for fibrosis has yet been identified, the systematic analysis of clinical data can be used to inform the development of therapeutical strategies tailored to suit the diverse aetiology of each fibrotic condition.
\end{abstract}

Keywords Fibrosis $\cdot$ Myofibroblasts $\cdot$ Treatment $\cdot$ TGF- $\beta$ - Extracellular matrix $\cdot$ Clinical trial

\section{Introduction}

\section{Background and Rationale of the Study}

Despite extensive investments and research efforts, no such thing as a "cure for fibrosis" has been as of yet discovered, and replacement of the affected organ remains the most frequent treatment strategy. There are several factors that render fibrosis treatment a challenging matter [1]. Aside from its inherently heterogeneous nature (i.e. it is not a distinct pathology, but rather an umbrella term covering a wide spectrum of conditions), fibrosis often represents a pathological end-state, and in

This article is part of the Topical Collection on Medicine

Alessandro Siani

alessandro.siani@port.ac.uk

1 School of Biological Sciences, University of Portsmouth, King Henry Building, King Henry 1st Street, Portsmouth PO1 2DY, UK most cases, it is only diagnosed after tissue degeneration has already taken place to a significant extent. Moreover, the increased deposition of highly cross-linked extracellular matrix (ECM) represents a significant physical barrier to the delivery of therapeutical agents to the affected tissue. As mentioned in the previous section, clinical intervention is further complicated by the self-sustaining nature of myofibroblasts that, by secreting profibrotic cytokines and generating tensile force, produce a local environment permissive to the persistence and propagation of fibrosis [2].

Given their fundamental role in the onset and progression of fibrosis, myofibroblasts are considered appealing pharmacological targets [3]. An increasing body of experimental evidence (summarized in Table 1) seems to indicate that the cytokines basic fibroblast growth factor (bFGF or FGF2), transforming growth factor $\beta 3$ (TGF- $\beta 3$ ), interferon $\gamma$ (IFN- $\gamma$ ), and interleukin-1 (IL-1) are appealing candidates for the pharmacological targeting of myofibroblasts [4]. While there indeed are several other compounds that have been shown to regulate myofibroblast activity in a preclinical 
Table 1 Preclinical evidence on the antifibrotic effect of the cytokines bFGF, IFN- $\gamma$, TGF- $\beta 3$, and IL-1

\begin{tabular}{|c|c|c|c|}
\hline Ref & Treatment & Model & Outcome \\
\hline [27] & FGF-2 (bFGF) & Wistar rats & $\begin{array}{l}\uparrow \text { Myofibroblast apoptosis } \\
\downarrow \alpha \text {-SMA expression }\end{array}$ \\
\hline [28] & FGF-2 (bFGF) & Porcine valvular interstitial cells & $\begin{array}{l}\downarrow \alpha \text {-SMA expression } \\
\downarrow \text { TGF- } \beta 1 \text { signalling } \\
\downarrow \text { Contraction }\end{array}$ \\
\hline [29] & FGF-2 (bFGF) & Porcine dermal cells & $\begin{array}{l}\downarrow \alpha \text {-SMA expression } \\
\downarrow \text { Cell spreading }\end{array}$ \\
\hline [30] & FGF-2 (bFGF) & Wistar rats & $\begin{array}{l}\uparrow \text { Myofibroblast apoptosis } \\
\downarrow \alpha \text {-SMA expression }\end{array}$ \\
\hline [31] & FGF-2 (bFGF) & Human adipose-derived mesenchymal stem cells & $\begin{array}{l}\downarrow \text { Cell spreading } \\
\downarrow \alpha \text {-SMA expression }\end{array}$ \\
\hline [32] & FGF-2 (bFGF) & $\mathrm{C} 57 \mathrm{BL} / \mathrm{ksJ} \mathrm{db} / \mathrm{db}$ mice & $\begin{array}{l}\uparrow \text { Myofibroblast apoptosis } \\
\downarrow \text { Scarring }\end{array}$ \\
\hline [33] & FGF-2 (bFGF) & New Zealand rabbits & $\begin{array}{l}\downarrow \text { Scarring } \\
\downarrow \alpha \text {-SMA expression }\end{array}$ \\
\hline [34] & FGF-2 (bFGF) & Human cardiac myofibroblasts & $\begin{array}{l}\downarrow \text { Contraction } \\
\downarrow \text { TGF- } \beta 1 \text { signalling } \\
\downarrow \text { ECM remodelling } \\
\downarrow \text { Cell spreading }\end{array}$ \\
\hline [35] & $\mathrm{IFN}-\gamma$ & Human skin fibroblasts and wound healing myofibroblasts & $\begin{array}{l}\downarrow \text { Contraction } \\
\downarrow \alpha \text {-SMA expression } \\
\downarrow \text { Total collagen production }\end{array}$ \\
\hline [36] & IFN- $\gamma$ & Wistar rats & $\begin{array}{l}\downarrow \text { Scarring } \\
\downarrow \alpha \text {-SMA expression } \\
\downarrow \text { Collagen III and IV expression }\end{array}$ \\
\hline [37] & IFN- $\gamma$ & Rat hepatic stellate cells & $\begin{array}{l}\downarrow \alpha \text {-SMA expression } \\
\downarrow \text { Proliferation } \\
\downarrow \text { Collagen I and IV expression } \\
\downarrow \text { Fibronectin expression }\end{array}$ \\
\hline [38] & IFN- $\gamma$ & Rat hepatic stellate cells & $\begin{array}{l}\downarrow \alpha \text {-SMA expression } \\
\downarrow \text { Proliferation }\end{array}$ \\
\hline [39] & IFN- $\gamma$ knockout & C57BL/6 mice & $\begin{array}{l}\uparrow \text { TGF- } \beta 1 \text { expression } \\
\uparrow \alpha \text {-SMA expression }\end{array}$ \\
\hline [40] & IFN- $\gamma$ & Wistar rats & $\begin{array}{l}\downarrow \text { Myofibroblast density } \\
\downarrow \text { Collagen III expression } \\
\downarrow \text { Hydroxyproline content }\end{array}$ \\
\hline [41] & IFN- $\gamma$ & Human gingival fibroblasts and myofibroblasts & $\begin{array}{l}\downarrow \alpha \text {-SMA expression } \\
\downarrow \text { Collagen I expression } \\
\downarrow \text { Cell spreading }\end{array}$ \\
\hline [42] & $\mathrm{IFN}-\gamma$ & WI-38 human fibroblasts & $\downarrow \alpha$-SMA expression \\
\hline [43] & IFN- $\gamma$ & Rat palatal fibroblasts & $\begin{array}{l}\downarrow \alpha \text {-SMA expression } \\
\downarrow \text { Pro } \alpha 2 \text { (I) collagen expression } \\
\downarrow \text { Contraction }\end{array}$ \\
\hline [44] & IFN- $\gamma$ & Human foetal lung fibroblasts & $\begin{array}{l}\downarrow \alpha \text {-SMA expression } \\
\downarrow \text { Cell spreading }\end{array}$ \\
\hline$[45,46]$ & IFN- $\gamma$ (free and PEGylated) & C57BL/6 mice; NIH3T3 mouse fibroblasts & $\begin{array}{l}\downarrow \text { Hydroxyproline content } \\
\downarrow \alpha \text {-SMA expression }\end{array}$ \\
\hline
\end{tabular}


Table 1 (continued)

\begin{tabular}{|c|c|c|c|}
\hline Ref & Treatment & Model & Outcome \\
\hline & & & $\begin{array}{l}\downarrow \text { Fibronectin expression } \\
\downarrow \text { Collagen I and III expression }\end{array}$ \\
\hline [47] & IFN- $\gamma$ & C57BL10J+/+ mice; muscle-derived fibroblasts & $\begin{array}{l}\downarrow \text { Total collagen production } \\
\downarrow \alpha \text {-SMA expression }\end{array}$ \\
\hline [48] & TGF- $\beta 3$ & Wistar rats; human dermal fibroblasts; rat dermal fibroblasts & $\begin{array}{l}\uparrow \text { Total collagen production (in vivo) } \\
\uparrow \alpha \text {-SMA expression (in vitro) }\end{array}$ \\
\hline [49] & TGF- $\beta 3$ & Sprague-Dawley rats & $\begin{array}{l}\downarrow \text { Scarring } \\
\downarrow \text { Fibronectin expression } \\
\downarrow \text { Collagen I and III expression }\end{array}$ \\
\hline [50] & TGF- $\beta 3$ & Human corneal fibroblasts (3D culture) & $\begin{array}{l}\downarrow \text { Collagen III expression } \\
\downarrow \alpha \text {-SMA expression }\end{array}$ \\
\hline [51] & TGF- $\beta 3$ transduction & CD1 mice; murine dermal fibroblasts & $\begin{array}{l}\downarrow \alpha \text {-SMA expression } \\
\downarrow \text { Scarring }\end{array}$ \\
\hline [52] & TGF- $\beta 3$ & $\mathrm{CL} /$ Fraser mice & $\begin{array}{l}\downarrow \text { Scarring } \\
\downarrow \text { Collagen I expression } \\
\downarrow \alpha \text {-SMA expression }\end{array}$ \\
\hline [53] & TGF- $\beta 3$ & C57BL/6 mice; human keloid fibroblasts & $\begin{array}{l}\downarrow \alpha \text {-SMA expression } \\
\downarrow \text { Collagen I expression } \\
\downarrow \text { Scarring }\end{array}$ \\
\hline [54] & IL- $1 \alpha$ & Human fibroblast/keratinocyte co-culture & $\begin{array}{l}\downarrow \alpha \text {-SMA expression } \\
\uparrow \text { NF- } k B \text { activation } \\
\downarrow \text { TGF- } \beta 1 \text { signalling }\end{array}$ \\
\hline [55] & IL-1 $\alpha / \beta$ (endogenous) & New Zealand rabbits & $\downarrow \alpha$-SMA expression \\
\hline [56] & $\mathrm{IL}-1 \alpha / \beta$ & Rabbit corneal myofibroblasts & $\uparrow$ Myofibroblast apoptosis \\
\hline [57] & IL-1 $\beta$ & Human dermal and lung fibroblasts & $\begin{array}{l}\downarrow \alpha \text {-SMA expression } \\
\downarrow \text { GLI1 expression } \\
\downarrow \text { Collagen I expression } \\
\downarrow \text { LOX expression } \\
\uparrow \text { MMP1, MMP2, MMP9, } \\
\quad \text { and MMP14 expressions }\end{array}$ \\
\hline [58] & IL-1 $\beta$ & Rat lung fibroblast & $\begin{array}{l}\uparrow \text { Myofibroblast apoptosis } \\
\downarrow \alpha \text {-SMA expression }\end{array}$ \\
\hline
\end{tabular}

setting, the evidence surrounding their effectiveness is sparse, and they have therefore been excluded from this review for the sake of conciseness.

While there is no shortage of in vitro and animal studies aimed at specifically triggering myofibroblasts apoptosis and/ or their reversal to a non-contractile phenotype, the clinical translatability of the findings remains mostly elusive [5]. At the time this review was written, a preliminary PubMed search for systematic reviews and meta-analysis using the $\mathrm{MeSH}$ term "Myofibroblasts" returned only 12 articles, 8 of which discussed the role of myofibroblasts in cancer. The remaining 4 articles were on the topic of fibrosis; however, 2 of them were focused on the identification of diagnostic markers, while the other 2 evaluated preclinical evidence, respectively, from studies on mice and rats.
The aim of the present paper is to research and systematically review published human clinical trials to evaluate current evidence on the pharmacological treatment of fibrosis, with specific regards to therapeutical strategies aimed at targeting the activity and persistence of myofibroblasts.

\section{Outline of Myofibroblast Biology and Ontology}

Myofibroblasts were first identified in the granulation tissue of healing skin wounds and described as a transient population of "modified fibroblasts" showing ultrastructural features typically associated with smooth muscle (SM) cells [6]. While the phenomenon of wound contraction was already known to researchers in the early twentieth century [7], the underlying cellular events remained elusive until the discovery that 
Fig. 1 Key hallmarks of the myofibroblast phenotype and main promoting/inhibiting factors

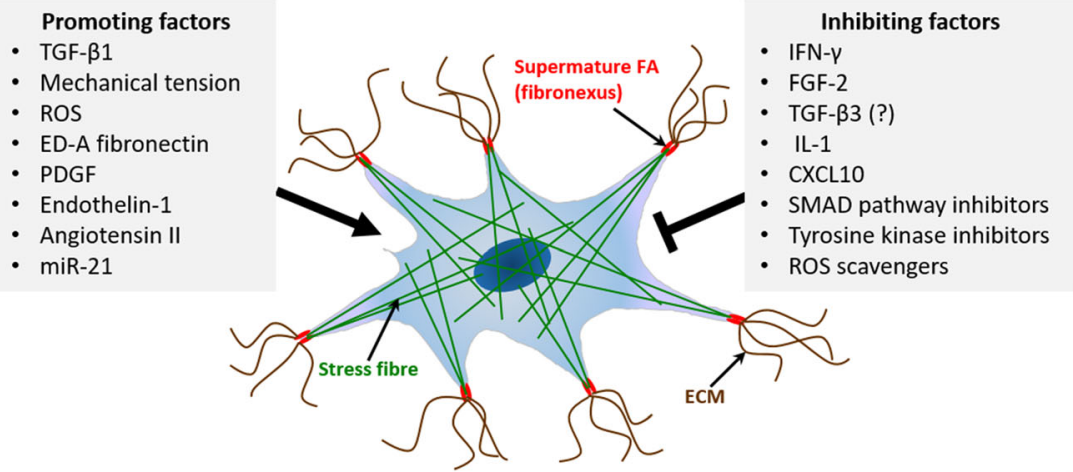

Biochemical and functional features of myofibroblasts

- $\alpha$-SMA expression and incorporation into stress fibres

- Expression of ED-A fibronectin

- Presence of supermature focal adhesions (fibronexi)

- ECM contraction and crosslinking

- Increased collagen synthesis (particularly collagen I, III, and IV)

- Altered TIMP/MMP expression and balance

- Vimentin overexpression

- Expression of collagen-crosslinking enzymes (lysyl oxidase and lysyl hydroxylase 2)

- Expression of OB-cadherin

- TGF-B1 secretion myofibroblasts could generate mechanical tension within the healing wound and contract the surrounding ECM, ultimately pulling together the wound edges and facilitating their closure $[8,9]$.

The distinctive biochemical, morphological, and functional features of myofibroblasts have been widely described and are summarized in Fig. 1. While myofibroblasts are akin to SM cells in the fact that they express $\alpha$-smooth muscle actin $(\alpha$ SMA) and are able to generate tractional forces, the former are characterized by the lack of concomitant expression of other SM-specific cell markers including SM myosin heavy chain, desmin, h-caldesmon, and smoothelin [5]. Moreover, unlike SM cells, myofibroblasts are typically characterized by the incorporation of actin into bundles of microfilaments known as stress fibres [10].

The overexpression of $\alpha$-SMA is crucial towards the maturation of focal adhesions (FA) into supermature focal adhesions (also referred to as fibronexi), characterized by a transmembrane association of contractile cytoskeletal elements and extracellular fibronectin (typically, the myofibroblast-specific ED-A fibronectin splice variant) [11]. The specialized transmembrane association of $\alpha$-SMA-positive stress fibres and extracellular ED-A fibronectin underpins the key functional feature of myofibroblasts, which is to generate tensional force and transmit it to the surrounding ECM [12].

ECM production and remodelling is a key hallmark of myofibroblast activity: in addition to the de novo synthesis and secretion of ED-A fibronectin, myofibroblasts are characterized by the deposition of other ECM components such as collagen (I, III, IV, V, VI) and proteoglycans, as well as by the secretion of matrix-crosslinking enzymes including lysyl oxidase (LOX) and lysyl hydroxylase 2 (LH2) [13, 14]. Fibrotic degeneration is also associated with an altered balance between matrix metalloproteinases (MMPs) and tissue inhibitors of metalloproteinases (TIMPs). Interestingly, while it would be reasonable to postulate that matrix-degrading enzymes exert an antifibrotic activity and their inhibitors a profibrotic one, that does not appear to always be the case, with the expression of different MMPs and TIMPs causing differential effects depending on their type and localisation [15].

The discovery of the fundamental role of myofibroblasts in physiological and pathological wound healing has spurred considerable research into their origin and differentiation mechanisms [16]. Traditionally, myofibroblasts were thought to exclusively arise from the activation of quiescent populations of local fibroblasts in response to a tissue injury. While this is frequently the case (particularly with regard to skin wounds), it is now clear that myofibroblasts can originate from a wide array of both mesenchymal and non-mesenchymal precursor cells $[17,18]$. Typical examples of mesenchymal precursors of myofibroblasts include fibrocytes, pericytes, SM cells, as well as adipose and bone marrow-derived stromal/ stem cells $[19,20]$. In addition, non-mesenchymal precursors have been shown to transdifferentiate into myofibroblasts via epithelial-mesenchymal transition (EMT) and endothelialmesenchymal transition (EndMT). Increasing evidence indicates that EMT and EndMT might play a role in the development and progression of renal and pulmonary fibrosis; howev$\mathrm{er}$, the in vivo significance of these pathways is still a matter of debate [21].

While myofibroblasts can originate from a wide range of precursor cells, the differentiation process in different tissues 
(and from different sources) is underpinned by a shared set of stimuli. It is widely accepted that the cytokine transforming growth factor $\beta 1$ (TGF- $\beta 1$ ) plays a central role in the development and maintenance of the myofibroblasts phenotype. Indeed, TGF- $\beta 1$ is not the sole biochemical factor responsible for the differentiation process. Multiple intracellular and extracellular molecular cues (summarized in Fig. 1) have been identified as myofibroblasts-inducing factors, including ECM components, growth factors, miRNAs, and reactive oxygen species (ROS) [22, 23].

Myofibroblasts have been described as a "paradigm for a mechanically active cell": both in vivo and in vitro, the mechanical properties of the cellular microenvironment direct the differentiation process in concert with soluble cues [24]. The formation of $\alpha$-SMA-negative stress fibres and mature FA can be observed at Young's moduli ranging from $\sim 3$ to $\sim 15 \mathrm{kPa}$, hallmarking the so-called proto-myofibroblast phenotype. Further increases in substrate stiffness result in the incorporation of $\alpha$-SMA in the stress fibres and in the supermaturation of FA [12]. Profibrotic mechanical signals are transduced both directly via the Rho cascade (due to the physical continuity of cytoskeletal and ECM components at FA sites) and indirectly via the release of latent TGF- $\beta 1$ stores from the ECM $[25,26]$. It is important to highlight that, by secreting TGF- $\beta 1$ and generating high levels of mechanical tension, myofibroblasts produce both of the "master regulators" that promote their own generation and survival; this positive feedback loop sustains their dysregulated persistence and activity, contributing to the well-documented difficulty of the clinical treatment of fibrosis [2].

\section{Methods}

This study was designed in accordance with PRISMA guidelines to research existing literature and investigate the impact of different pharmacological interventions (compared to placebo-treated or untreated controls) on patients affected by fibrotic disorders. The effectiveness of different therapeutical strategies was qualitatively assessed on the base of changes in fibrosis-associated biochemical, structural, and functional markers. Figure 2 provides a schematic representation of the search and selection process used in this review.
Fig. 2 Flow chart of the search and inclusion strategy used for this review, designed according to PRISMA guidelines

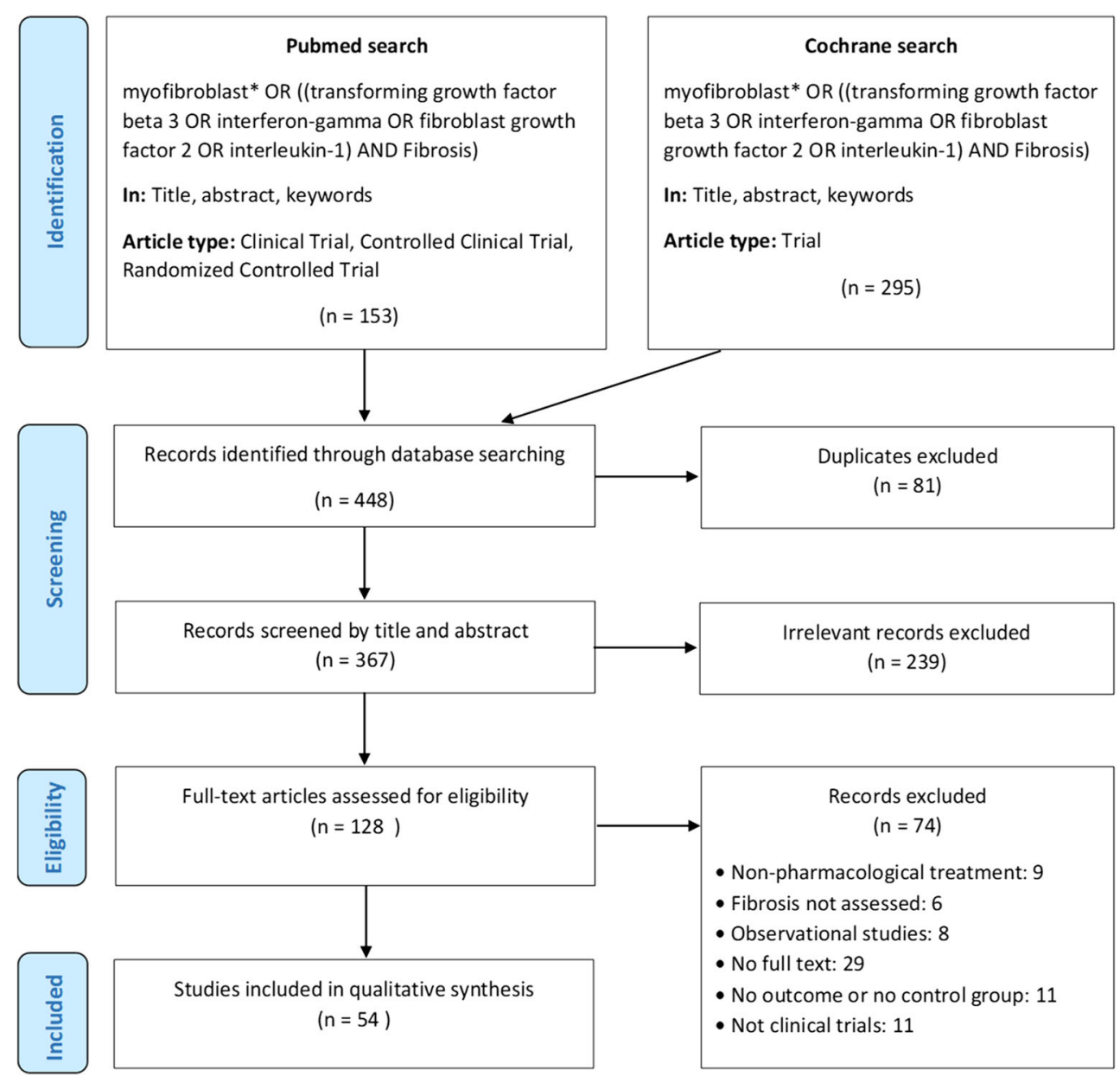




\section{Search Strategy}

Although their key role in the aetiology of fibrotic conditions is widely acknowledged, myofibroblasts are not always explicitly mentioned in clinical trials, that often focus on describing the specific condition (e.g. Dupuytren's disease), intervention (e.g. IFN- $\gamma$ administration), and measurable outcomes (e.g. reduction of TGF- $\beta 1$ levels) rather than the underlying cellular events. To overcome this limitation, the cytokines that had been preclinically identified as the most promising myofibroblast-inhibiting agents have been included in the search as proxies. Appropriate MeSH terms were used in all searches to ensure the inclusion of articles containing synonyms of the desired keywords. The search string (excluding quotation marks) "myofibroblast* OR ((transforming growth factor beta 3 OR interferon-gamma OR fibroblast growth factor 2 OR interleukin-1) AND fibrosis)" was used to search the PubMed and Cochrane databases, and the results were filtered by article type to only include human clinical trials.

\section{Exclusion/Inclusion Criteria}

The following exclusion criteria were applied while screening titles and abstracts: (e1) duplicated references, (e2) articles not in English, (e3) studies not on human patients, (e4) content irrelevant to the aims of the study. The remaining articles were evaluated for eligibility using the following inclusion criteria: (i1) full text available, (i2) not a conference abstract book or poster, (i3) human patients with fibrotic disease, (i4) pharmacological intervention carried out, (i5) outcome provided, (i6) fibrosis/myofibroblast marker(s) assessed with reference to a control group.

\section{Results}

After screening and evaluation of the search results, a total of 54 clinical trials (schematically described in Table 2) were deemed eligible for qualitative discussion. The majority of the eligible articles focused on fibrotic degeneration of the respiratory system (16 articles), skin (14 articles), liver (10 articles), and kidney (8). In the interest of clarity, the results are grouped and presented on the base of the affected organ targeted in the clinical trials. Due to the relative shortage of information, fibrotic conditions discussed in 3 or less of the eligible articles are pooled together in "Other Organs and Syndromes".

\section{Lungs and Airways}

\section{Idiopathic Pulmonary Fibrosis}

Amongst the papers identified in this study, pharmacological treatment of idiopathic pulmonary fibrosis (IPF) was the subject of 8 clinical trials, 6 of which tested the effects of IFN- $\gamma$ administration on IPF patients. Despite the shortage of conclusive data on their efficacy, systemic corticosteroids are frequently prescribed to IPF patients. Ziesche and colleagues investigated the effects of supplementing a low-dose prednisolone regime with IFN- $\gamma$ on IPF patients who did not respond to glucocorticoids [59]. While lung function declined in all patients in the prednisolone-only group, significant increases from the baseline were observed in arterial $\mathrm{pO}_{2}$ and lung capacity in the prednisolone plus IFN- $\gamma$ group. A successive study analysed biomarkers' levels in lung biopsies and bronchoalveolar lavage fluid (BALF) of IPF patients treated with IFN- $\gamma$, concluding that "IFN- $\gamma$ downregulates molecules associated with fibrosis, proliferation, and inflammation, and upregulates molecules associated with antimicrobial defense and antiangiogenesis" [60]. The effect of IFN- $\gamma$ on alleviating functional markers of fibrosis was further confirmed by the observation that IFN- $\gamma$ treatment caused an improvement in total lung capacity (TLC), diffusing capacity of the lungs for carbon monoxide (DLCO), and arterial $\mathrm{pO}_{2}$ in IPF patients [61, 62]. However, two placebo-controlled randomized trials involving respectively 330 and 826 IPF patients not only failed show any improvement following IFN- $\gamma$ treatment but also reported significant adverse effects. In the first of the two studies, IFN- $\gamma$-treated patients did not show any improvement in lung function, gas exchange, and quality of life [63]. Moreover, an increase in cases of pneumonia and constitutional symptoms was observed in the treatment group compared to the placebo group. Similarly, the INSPIRE trial was prematurely stopped due to the lack of improvement in IFN- $\gamma$ treated patients compared to the control group, and the observation that nearly all treated patients experienced at least one adverse effect, with several subjects showing increased constitutional symptoms [64].

The tyrosine-kinase inhibitor nintedanib has been used as an alternative to corticosteroids for the treatment of IPF. Two replicate randomized phase III trials (INPULSIS-1 and INPULSIS-2) were carried out to verify the effectiveness and safety of nintedanib compared to placebo on 1066 IPF patients [65]. Despite the onset of diarrhoea in $<5 \%$ of the subjects, patients in the treatment group showed a reduction in the decline of forced vital capacity (FVC), suggesting that nintedanib administration might be a promising strategy for IPF treatment. Conversely, a recent phase II randomized trial indicated that neutralization of circulating interleukin-4 and interleukin-14 via the bispecific immunoglobulin SAR156597 did neither ameliorate lung functionality (FVC and DLCO) nor reduced disease progression/mortality in IPF patients [66].

Serum amyloid P (SAP, also known as pentraxin 2) physiologically regulates differentiation of circulating monocytes into fibrocytes and has shown antifibrotic potential in animal experiments. Its pharmacokinetics, safety, and efficacy in 
Table 2 Summary of clinical studies identified via systematic search. All abbreviations used in this table are described in the main body of the text. *Current status is indicated as $\mathrm{M}$ if the drug is marketed in one or more countries for the specific use described in the trial, MO if marketed for other uses, NM if non-marketed

\begin{tabular}{llcl}
\hline Ref Treatment & Key outcomes & Side effects & Currents \\
status
\end{tabular}

[59] Subcutaneous IFN- $\gamma$ in IPF patients

[60] Subcutaneous IFN- $\gamma 1 \mathrm{~b}$ in IPF patients

[61] Inhaled IFN- $\gamma$ in IPF patients

[62] Subcutaneous IFN- $\gamma$ or colchicine in IPF patients

[63] Subcutaneous IFN- $\gamma 1 \mathrm{~b}$ in IPF patients

[64] Subcutaneous IFN- $\gamma$ 1b in IPF patients

[65] Oral nintedanib in IPF patients

[66] Subcutaneous SAR156597 in IPF patients

[67] Intravenous recombinant SAP (pentraxin-2) in PF patients

[68] Intravenous recombinant SAP (pentraxin-2) in IPF patients

[69] Inhaled beclomethasone dipropionate in asthma patients

[70] Inhaled budesonide or combined budesonide/formoterol in asthma patients

[71] Oral montelukast in mild asthma patients

[72] Inhaled IFN- $\gamma 1 \mathrm{~b}$ in patients with cystic fibrosis lung disease

[73] Subcutaneous IFN- $\gamma 1 \mathrm{~b}$ and oral prednisolone in bronchiolitis patients

[74] Inhaled fluticasone propionate in clinically No improvement in FEV and BOS occurrence Not discussed stable lung transplant recipients

[75] Intradermal avotermin (human recombinant TGF- $\beta 3$ ) in skin wounds (healthy volunteers)

[76] Intradermal avotermin in skin wounds (healthy volunteers) $\uparrow \mathrm{pO}_{2}$

$\uparrow$ Lung capacity

$\downarrow$ Fibrosis, proliferation, and inflammation markers

$\uparrow$ Antimicrobial and antiangiogenesis markers

$\uparrow$ IFN- $\gamma$ lung deposition

Cough

MO

$\uparrow$ IFN- $\gamma$ in BAL

No therapeutic conclusions were drawn

$\downarrow$ TGF- $\beta 1$ expression in colchicine group

Not discussed

MO

$\downarrow$ IL-18 in BAL for both groups

$\uparrow$ DLCO in IFN- $\gamma$ group

$\uparrow \mathrm{pO}_{2}$ in IFN- $\gamma$ group

No improvement in lung function, gas exchange, and quality of life.

No improvement in clinical symptoms and survival

$\downarrow$ FVC decline rate

No improvement in FVC, DLCO, and mortality.

$\downarrow$ Fibrocyte count in whole blood

$\downarrow$ FVC decline rate

$\uparrow 6$-min walking distance

$\downarrow$ Collagen III and TIMP1

$\downarrow$ Myofibroblasts and inflammatory cells

$\uparrow$ MMP-9

$\uparrow \mathrm{FEV}_{1}$ and DMin

$\downarrow$ Sputum eosinophilia in both groups

$\downarrow$ Submucosal myofibroblasts in combined treatment group

$\downarrow$ Late asthmatic response in combined treatment group

$\downarrow$ Airway wall myofibroblasts

$\downarrow$ Lymphomononuclear cells

$\uparrow$ Neutrophils

No improvement in FEV and sputum bacteria density

Dyspnea, hemoptysis, pulmonary congestion, exacerbation of symptoms

Headache, fever, rigours, myalgia, influenza-like symptoms

Cough, headache, fatigue, influenza-like symp-

$\mathrm{MO}$ toms

Diarrhoea

M

Worsening of IPF, cough, diarrhoea, viral upper respiratory tract infection, bronchitis

No differences compared to placebo

Cough

NM

Not discussed

M

Not discussed

M

$\uparrow$ FEV1

$\downarrow$ Dyspnea and hospitalization

Not discussed

MO

MO

Improved scar VAS score

Transient erythema and oedema

NM

Improved scar VAS score

Incidence comparable to placebo

NM 
Table 2 (continued)

Ref Treatment
Key outcomes
Side effects

Current

status*

[77] Intradermal avotermin in varicose leg veins Improved scar VAS score removal surgery patients

[78] Intradermal avotermin in scar revision surgery patients
Improved scar VAS score

$\downarrow$ Scar surface area
Incidence comparable to placebo

NM

Incidence comparable to placebo

Four serious adverse events possibly related to treatment

Not discussed

$\uparrow$ Collagen bundle organization

$\downarrow$ Post-operative scar colour change

[80] Topical bFGF (FGF-2) in paediatric second-degree burn patients

$\uparrow$ Skin/scar colour match

Not discussed

$\downarrow$ Hypertrophic scar formation

Improved scar pigmentation, pliability, height and vascularity after one year

[81] Intralesional IFN- $\gamma$ in keloid scar patients $\quad \downarrow$ Keloid height

$\downarrow$ Collagen bundles thickness

$\downarrow$ Neutrophils in stratum corneum

NM

Transient headache and myalgia, both resolved within $4 \mathrm{~h}$
No improvement in lesion size and collagen I production

$\downarrow$ mLoSSI score

$\downarrow$ Skin hardness

$\downarrow$ Dermal infiltration

$\downarrow$ Reticular dermis fibrosis

Arthralgia, fatigue, and dizziness

$\mathrm{MO}$

Mild transient burning sensation at the site of application localized scleroderma

[85] Oral nilotinib in patients with diffuse cutaneous systemic sclerosis

Patients with a decrease in MRSS showed a Asymptomatic changes in liver function test concomitant overexpression of TGFBR and 2 Patients required hospitalization due to SAE PDGFRB

[86] Intravenous rituximab in systemic sclerosis $\uparrow$ Dickkopf- 1 expression patients

$\downarrow$ Dermal TGF- $\beta$ expression

$\uparrow$ Resolution of skin fibrosis

Not discussed

$\downarrow$ TGF- $\beta$-regulated markers $\downarrow$ Myofibroblast infiltration Improved MRSS score systemic sclerosis

$\downarrow$ Circulating TGF- $\beta$ levels

[88] Extracorporeal photochemotherapy in patients with diffuse cutaneous systemic sclerosis

\section{$\downarrow$ Dermal thickness}

Improved MRSS score

[89] Intramuscular IFN- $\gamma$ in Hepatitis B patients $\downarrow$ Hepatic fibrosis score with hepatic fibrosis

$\downarrow$ Inflammatory score

$\downarrow$ Nuclear Smad2

$\downarrow$ Hepatic stellate cells
Anaemia, GI and gingival bleeding

None observed

Transient fever, headache, muscular, skeletal and MO limb pain, nausea, and decreased white blood cell and platelet counts
[90] Subcutaneous IFN- $\gamma$ in hepatitis C patients with hepatic fibrosis

[91] Intramuscular IFN (subtype not specified) and/or oral perindopril in patients with refractory chronic hepatitis $\mathrm{C}$

[92] Subcutaneous IFN- $\gamma$ lb in hepatitis C patients with advanced hepatic fibrosis or cirrhosis
Aggregate data show no significant antifibrotic Increased liver enzymes in one patient effect, however a reduction in fibrosis was observed in selected patients

$\downarrow$ Serum fibrosis markers in perindopril and combination group

$\downarrow$ TGF- $\beta$ levels in combination group

No improvement in viral load and Ishak fibrosis score
Headache, fatigue, rigours, myalgia, arthralgia, pyrexia, influenza-like illness, pain, and muscle cramps 
Table 2 (continued)

Ref Treatment
Key outcomes

Side effects

Current

status*
[93] Oral telmisartan or losartan in hepatitis C patients on a ribavirin/pegylated IFN- $\alpha$ 2a regime

[94] Oral salvianolic acid B in hepatitis B patients with hepatic fibrosis on a IFN- $\gamma$ Improvement in ultrasound imaging score regime

[95] Korean red ginseng in hepatitis C patients $\downarrow$ Serum hyaluronic acid and TGF- $\beta$ levels with hepatic fibrosis on an antiviral regime

[96] Oral pioglitazone or vitamin $\mathrm{E}$ in patients with non-alcoholic steatohepatitis

[97] Oral pioglitazone or vitamin E in patients with non-alcoholic steatohepatitis

[98] Subcutaneous pegbelfermin in non-alcoholic steatohepatitis patients

[99] Microemulsion cyclosporin or tacrolimus in kidney transplant recipients

[100] CNI withdrawal or maintenance in kidney transplant recipients

$\downarrow$ Serum AST, GGT, and TGF- $\beta$ levels in telmisartan group

$\downarrow$ Serum fibrosis markers aminotransferase in both groups in both groups

Improved histological features in vitamin $\mathrm{E}$ group

$\downarrow$ Shh signalling

$\downarrow$ Myofibroblast accumulation

$\downarrow$ Hepatic fat fraction

$\downarrow$ Liver stiffness

$\downarrow$ Serum PRO-C3 closporin group group
None observed

Headache and drowsiness in both telmisartan and MO losartan group

None observed $\mathrm{MO}$ (TCM)

Weight gain in pioglitazone group

$\downarrow$ Hepatic steatosis and globular inflammation

$\uparrow$ Collagen III and TIMP-1 expression in cy-

$\uparrow$ Collagen and $\alpha$-SMA in CNI maintenance

$\uparrow$ TGF- $\beta$ signalling in CNI maintenance group

$\downarrow$ Enhancement of chronicity index in CNI withdrawal group

$\downarrow$ Myofibroblasts in withdrawal group

[101] CNI-containing or CNI-free immunosup- $\quad \downarrow$ Serum TGF- $\beta$ levels in CNI-free group pressive regime on kidney transplant re- $\downarrow$ Tubular lesions in CNI-free group cipients

[102] CNI-containing or CNI-free immunosup- No significant differences in fibrosis pressive regime on kidney transplant reprogression cipients

[103] Oral losartan in hypertensive kidney transplant recipients

$\downarrow$ Plasma TGF- $\beta 1$ levels

$\downarrow$ Histopathological progression rate

[104] Oral spironolactone in patients with chronic $\downarrow$ Urinary TGF- $\beta 1$ levels kidney disease

$\downarrow$ Proteinuria

[105] Oral aliskiren or perindopril in patients with $\uparrow$ Plasma renin levels in both groups non-diabetic kidney disease

$\uparrow$ Urinary TGF- $\beta 1$ levels in both groups

$\downarrow \alpha$-SMA expression

$\downarrow$ Mesangial cell proliferation

$\downarrow$ ECM accumulation diffuse proli

No improvements observed in intraocular pressure, bleb vascularity, and trabeculectomy failure rate

tients undergoing first-time trabeculectomy

[108] Intravitreal bevacizumab in patients with proliferative diabetic retinopathy
Not discussed

Diarrhoea, GI-related adverse events, one case of NM worsened depression

Not discussed

M

Not discussed M rejection in the CNI-free group. Leukopenia and gingival hypertrophy in CNI-treated

None observed

None observed

Not discussed

None observed

MO

None observed

NM

Not discussed

MO
Not discussed

Aphthous stomatitis, acne, rash and graft $\uparrow$ Cell apoptosis

No improvement observed in $\alpha$-SMA expression and collagen deposition 
Table 2 (continued)

\begin{tabular}{|c|c|c|c|c|}
\hline Ref & Treatment & Key outcomes & Side effects & $\begin{array}{l}\text { Current } \\
\text { status* }\end{array}$ \\
\hline [109] & $\begin{array}{l}\text { Topical tranilast in patients with lacrimal } \\
\text { gland GVHD }\end{array}$ & $\begin{array}{l}\text { Improvements in Rose Bengal and Schirmer } \\
\text { test score }\end{array}$ & None observed & MO \\
\hline [110] & $\begin{array}{l}\text { Oral fluimucil in patients with acute } \\
\text { myocardial infarction }\end{array}$ & $\downarrow$ Blood TGF- $\beta 1$ levels & Not discussed & MO \\
\hline [111] & $\begin{array}{l}\text { Preoperative palmar injection of } \\
\text { depo-medrone in patients with } \\
\text { Dupuytren's disease }\end{array}$ & $\begin{array}{l}\uparrow \text { Apoptosis of macrophages and fibroblasts } \\
\downarrow \text { fibroblast proliferation }\end{array}$ & Not discussed & MO \\
\hline [112] & $\begin{array}{l}\text { Intranodular adalimumab in patients with } \\
\text { Dupuytren's disease }\end{array}$ & $\downarrow \alpha$-SMA and procollagen I protein levels & $2 \mathrm{SAE}$ thought to be independent from treatment & MO \\
\hline [113] & $\begin{array}{l}\text { Oral tadalafil and/or intralesional verapamil } \\
\text { in patients with Peyronie's disease }\end{array}$ & $\begin{array}{l}\text { Improved clinical symptoms in combination } \\
\text { group }\end{array}$ & $\begin{array}{l}\text { Hematoma at the injection site, dyspepsia, } \\
\text { headache, back pain, myalgia, flushing }\end{array}$ & MO \\
\hline
\end{tabular}

treating pulmonary fibrosis were initially assessed in a smallscale placebo-controlled randomized clinical trial involving 26 healthy volunteers and 3 patients with pulmonary fibrosis [67]. The study indicated that recombinant SAP was well tolerated and resulted in a significant (30-50\%) reduction in circulating fibrocytes in PF patients after $24 \mathrm{~h}$ from administration. More recently, a larger randomized placebo-controlled phase II trial corroborated the preliminary results: SAP-treated IPF patients exhibited significant reduction in FVC decline and improved scores in the 6-min walk test [68].

\section{Asthma}

Airway remodelling and fibrotic degeneration are frequently associated with chronic inflammation in asthmatic patients, a process in which myofibroblasts are known to play a crucial role. Inhaled corticosteroids are effective in the management of asthma, and have been shown to reduce inflammation and airways remodelling. Asthmatic patients treated with beclomethasone dipropionate exhibited a significant reduction in collagen III deposition and a concomitant decrease of MMP-9 and increase of TIMP-1 [69]. A significant reduction in the numbers of myofibroblasts and inflammatory cells (eosinophils, mast cells, and lymphocytes) was observed in the lamina propria and submucosa of beclomethasone-treated patients compared to the placebo-treated group.

In a different study, the effect of the corticosteroid budesonide was evaluated alone or in combination with the $\beta 2$-agonist formoterol [70]. The combined treatment of asthmatic patients with formoterol and budesonide reduced sputum eosinophilia significantly more than budesonide on its own. Remarkably, while budesonide failed to attenuate the increase in submucosal myofibroblast numbers following antigen inhalation, the combined treatment reduced their number to near-baseline levels.

A reduction in the number of submucosal myofibroblasts, lymphomononuclear cells, and macrophages was also observed in antigen-challenged asthmatic patients after treatment with the leukotriene receptor antagonist montelukast [71]. Interestingly, the number of lymphocytes increased after montelukast treatment, and no effect was observed on eosinophils and mast cells.

\section{Respiratory System-Others}

In addition to its use as a putative therapeutic agent for IPF (as discussed earlier on), IFN- $\gamma$ has been investigated as potential treatment of other fibrotic pathologies; however, its efficacy and safety remain unclear. In 2004, a placebo-controlled randomized trial showed that aerosolized IFN- $\gamma$ failed to both improve FEV and reduce sputum bacterial density in patients with cystic fibrosis lung disease and caused an exacerbation of pulmonary symptoms at higher dosages [72]. However, combined treatment with IFN- $\gamma$ and prednisolone successfully ameliorated respiratory symptoms in patients suffering from bronchiolitis obliterans resulting from exposure to mustard gas in the 1980-1988 Iran-Iraq war [73]. After six months of treatment, the IFN- $\gamma /$ prednisolone group showed significant improvement in FEV1 and reduction in dyspnea and hospitalization compared to the prednisolone-only control group. In a different study, fluticasone propionate was used to prevent bronchiolitis obliterans syndrome (BOS) in clinically stable lung transplant recipients [74]. Interestingly, BALF TGF- $\beta 1$ levels increased considerably within the fluticasone-treated group; however, the difference between case and control group was not statistically significant. No significant 
difference in FEV scores and BOS occurrence was observed between the two groups.

\section{Skin}

\section{Wound Healing}

The last decade has seen an upsurge of clinical research aimed at minimizing scarring following skin wounds. The results of three phase I/II randomized trials investigating the use of avotermin (human recombinant TGF- $\beta 3$ ) as a potential antiscarring therapeutical agent were described in a 2009 Lancet paper [75]. Intradermal avotermin administration significantly reduced scarring compared to placebo; post-healing histological analysis showed that the ECM of avotermin-treated wounds resembled that of normal skin more closely than placebo-treated wounds. A successive study further confirmed the anti-scarring effect of different regimes of intradermal avotermin, indicating that treatment with 50 to $200 \mathrm{ng}$ avotermin/100 $\mu \mathrm{l} /$ linear cm significantly improves scar appearance at 6 and 12 months after wounding [76]. While the trials described above were performed on healthy volunteers, two further studies by the same research group confirmed the scar-reducing effect of intradermal avotermin administration in patients undergoing, respectively, scar revision surgery and varicose vein removal surgery $[77,78]$.

The cytokine bFGF (FGF-2) has shown considerable preclinical evidence of antifibrotic activity. Skin graft recipients treated with topical bFGF showed a reduction in postoperative scar colour change compared to placebo-treated controls; histological analysis of skin biopsies showed an improvement in dermal arrangement, a wider cytoplasmic area, and more organized collagen bundles [79]. Similar results were obtained following topical bFGF administration in paediatric second-degree burn victims [80]. A marked decrease in the number of hypertrophic scarring events was observed after 1 year in the bFGF-treated patients, whose scars showed significant improvements in terms of pigmentation, pliability, height, and vascularity compared to placebo-treated controls.

\section{Keloids}

Two independent placebo-controlled trials conducted in the 1990 s evaluated the effect of IFN- $\gamma$ administration as an anti-scarring treatment for keloids. In the former, intralesional IFN- $\gamma$ injection resulted in a statistically significant reduction of keloid height (no changes were observed in lateral dimensions) and visible histological changes, most notably the absence of neutrophils in the stratum corneum and a reduction in collagen bundle thickness [81]. In the latter, IFN- $\gamma$ was administered three weeks after surgical excision of the keloids to prevent their recurrence. At 12 weeks and 13 months postoperation, no significant variation in keloid recurrence and size could be observed between patients treated with IFN- $\gamma$ and placebo [82]. It is worth mentioning that both trials involved a small number of subjects ( 8 and 7 respectively), which could explain the contradictory findings on the effectiveness of IFN- $\gamma$ administration.

\section{Localized Scleroderma and Systemic Sclerosis}

Patients with localized scleroderma were administered subcutaneous IFN- $\gamma$ or placebo intralesionally over a period of 6 weeks and tested for 18 weeks thereafter [83]. Interestingly, although the treatment did not affect lesion size and collagen I production, patients treated with IFN- $\gamma$ showed a reduction in new lesions, indicating that IFN- $\gamma$ might exert a prophylactic rather than therapeutic function.

In a different phase II study, administration of topical pirfenidone resulted in a reduction of the modified Localized Scleroderma Skin Severity Index (mLoSSI) and skin hardness in patients with localized scleroderma [84]. Histopathological analysis of the lesions also highlighted a reduction in dermal infiltration and reticular dermis fibrosis following pirfenidone treatment.

The tyrosine kinase inhibitor nilotinib has been tested for its ability to interfere with profibrotic signalling pathways in systemic sclerosis (SSc). Patients that exhibited higher improvements in modified Rodnan skin score (MRSS) following systemic administration of nilotinib showed a concomitant overexpression of genes associated with TGFBR and PDGFRB signalling, indicating a correlation between the inhibition of the TGF- $\beta$ and PDGF pathways and amelioration of skin fibrosis [85].

Immunomodulatory monoclonal antibodies have shown promising potential for the treatment of systemic sclerosis. Targeting CD20 ${ }^{+}$cells with rituximab (RTX) resulted in the overexpression of the Wnt pathway inhibitor Dickkopf-1 in systemic sclerosis patients [86]. Moreover, RTX-treated patients showed a marked reduction in dermal TGF- $\beta$ (subtype not specified) expression; histological analysis highlighted enhanced resolution of skin fibrosis following treatment, indicating that RTX-mediated B cell depletion might be an efficient strategy for the treatment of fibrotic conditions with an autoimmune aetiology. Fresolimumab (a monoclonal antibody targeting all TGF- $\beta$ isoforms) was used to treat patients with early diffuse SSc. Fresolimumab-mediated TGF- $\beta$ Inhibition resulted in a significant downregulation of TGF- $\beta$-regulated biomarkers, a reduction in dermal myofibroblast infiltration, and a drastic improvement of clinical symptoms of fibrosis, supporting the observation of a causative role of TGF- $\beta$ signalling in SSc aetiology [87].

Immunomodulation via extracorporeal photochemotherapy (ECP) was successfully used to attenuate fibrosis progression in patients with diffuse cutaneous SSc [88]. Following ECP treatment, patients showed a decrease in dermal thickness, 
improvements in modified Rodnan skin score, and a significant reduction in circulating TGF- $\beta$ levels.

\section{Liver}

\section{Fibrosis in Patients with Chronic Viral Hepatitis}

Out of the 10 trials identified in this study that focused on the treatment of liver fibrosis, 7 involve patients who developed the condition as a consequence of chronic viral hepatitis, reflecting the key role of $\mathrm{HBV}$ and $\mathrm{HCV}$ infection in the aetiology of liver fibrosis.

Due to their established activity as both antiviral and antifibrotic agents, interferons have been widely investigated as therapeutic agents for the treatment of viral hepatitis and prevention of the associated liver fibrosis. In a randomized controlled trial, HBV-positive patients were treated with intramuscular IFN- $\gamma$ over a period of 9 months [89]. While no significant difference in viral load was observed between the two groups, patients in the treatment group showed a significant reduction in hepatic fibrosis score and inflammatory score compared to the control. Moreover, immunohistochemical analysis indicated that IFN- $\gamma$ treatment resulted in a marked reduction in nuclear Smad2 and in the number of hepatic stellate cells (HSC, a myofibroblasts-like $\alpha$-SMApositive cell type); these findings are consistent with a repression of TGF- $\beta$ signalling in HSC and hepatocytes. Comparable observations (unchanged viral load, reduction in fibrosis score, and $\alpha$-SMA immunoreactivity) were reported after treatment of HCV-positive patients with subcutaneous IFN- $\gamma$ [90]. Interestingly, the results of a different trial published in the same year indicated that while treatment with interferon alone (subtype not specified) could not decrease serum fibrosis markers in patients with chronic HCV infection, it did significantly potentiate the antifibrotic effect of the ACE inhibitor perindopril [91]. A multicentre randomized placebo-controlled trial was carried out to evaluate the antifibrotic effects of IFN- $\gamma 1 \mathrm{~b}$ in 502 patients with chronic $\mathrm{HCV}$ infection [92]. While IFN- $\gamma 1 \mathrm{~b}$ was generally well tolerated, no significant differences in viral load and Ishak fibrosis score were observed between the case and control groups. A regime of subcutaneous pegylated IFN- $\alpha 2$ a was supplemented with AT1 antagonists (either telmisartan or losartan) in HCV-positive patients [93]. No significant changes in rapid (RVR) and early (EVR) virological response were observed between the treatment groups; however, treatment with telmisartan resulted in significant decreases in serum TGF- $\beta 1$ levels and urinary hydroxyproline and a concomitant reduction in Ishak fibrosis score.

Salvia miltiorrhiza (red sage) is frequently used in traditional Chinese medicine (TCM) for the treatment of liver fibrosis and cirrhosis, and its derivative salvianolic acid B (SA-B) has been shown to exhibit antifibrotic activity in preclinical studies.
The effectiveness and safety of SA-B for the treatment of liver fibrosis in HBV-positive patients were evaluated in comparison to IFN- $\gamma$ and placebo [94]. While no reduction in HBV load was observed, both SA-B and IFN- $\gamma$ caused an amelioration of inflammatory and fibrotic score compared to placebo, further suggesting that the antifibrotic effect of the treatment may not be directly caused by a reduction in viral titre. Similarly, while no further reduction of HBV viral load was observed when supplementing antiviral therapy with ginseng extract (also frequently used in TCM as an antifibrotic agent), the combined treatment resulted in a significant reduction in serological markers of liver fibrosis (TGF- $\beta$ and hyaluronic acid) [95].

\section{Fibrosis in Patients with Non-alcoholicFibrosis in Patients with Non-alcoholic}

SteatohepatitisNon-alcoholic steatohepatitis (NASH) is an increasingly prevalent pathology in developed countries, and is often associated with liver fibrosis. The PIVENS trial was carried out to assess the therapeutic effect of pioglitazone or vitamin $\mathrm{E}$ (VitE) in NASH patients [96]. Although treatment with pioglitazone resulted in a reduction in steatosis and lobular inflammation, only VitE caused a significant rate of improvement in NASH patients. A successive study based on the PIVENS trial reported that the amelioration of NASH symptoms following VitE treatment correlates with a reduction in both Shh signalling and myofibroblast accumulation [97]. NASH patients with liver fibrosis stages 1-3 were enrolled in a multicentre randomized phase IIa trial to evaluate the safety and efficacy of pegbelfermin (PEGylated human FGF21) [98]. Pegbelfermin treatment caused a significant reduction in hepatic fat fraction, liver stiffness, and serum PROC3 (N-terminal type III collagen propeptide, an established fibrosis marker) compared to placebo.

\section{Kidney}

\section{Renal Allograft Fibrosis}

Post-transplantation chronic allograft nephropathy is typically characterized by tubulointerstitial fibrosis, glomerulosclerosis, and vascular sclerosis ultimately resulting in allograft failure. A substantial body of research has gone into investigating immunosuppression strategies to prevent both allograft rejection and fibrotic degeneration. The calcineurin inhibitors (CNI) cyclosporine and tacrolimus are routinely administered to kidney transplant patients as immunosuppressive agents; however, CNI use has been linked to the insurgence and progression of kidney fibrosis. A randomized clinical trial designed to test the differential effect of the two drugs on the expression of fibrosis-associated genes indicated that cyclosporin treatment resulted in a higher expression of collagen III and TIMP-1 compared to tacrolimus after a week post- 
transplant [99]. While these findings might suggest that tacrolimus could be a more efficient immunosuppressive agent to prevent the development of fibrosis in allograft recipients, it is worth mentioning that no significant difference in the expression of the analysed profibrotic markers could be observed at 3 and 6 months post-transplant. In addition to tacrolimus, other macrolide immunosuppressors (sirolimus and everolimus) have been tested in kidney transplant recipients for potential profibrotic activity. The effects of early withdrawal from a CNI regime were tested in a randomized trial, whereby patients on a combined regime of tacrolimus, sirolimus, and prednisone were randomized in two groups; one group (SRL) received no tacrolimus and an increased dose of sirolimus, and the other group (TAC) was maintained on a tacrolimus regime [100]. Maintenance of tacrolimus resulted in an increase in collagen and $\alpha$-SMA, as well as in TGF- $\beta$, its receptors TGF- $\beta$-R1 and R2, and p-Smad2/3, indicating the presence of a sustained profibrotic signal mediated by the TGF- $\beta / \mathrm{Smad}$ pathway and resulting in myofibroblast activation, consistently with previous reports of CNI-induced kidney fibrosis. Similar results were obtained in another trial comparing the effects of CNI-containing and CNI-free immunosuppressive regimens: allograft recipients were treated with mycophenolate mofetil (MMF), prednisone, daclizumab (CNI-free group) or MFF, prednisone, and cyclosporine (CNI group) [101]. After 1 year from transplantation, the CNI group exhibited a significantly higher serum TGF- $\beta 1$ concentration and interstitial fibrosis/tubular atrophy. However, a different study reported that cyclosporine withdrawal failed to reduce fibrosis progression [102]. Patients on a cyclosporine regime were randomized to either maintain cyclosporine administration or switch to a non-CNI regime (everolimus). No significant reduction in interstitial fibrosis/tubular atrophy was observed in the non-CNI group. Moreover, cyclosporine withdrawal resulted in a marked increase in biopsy-proven acute rejection, indicating that a CNI regime might be necessary to maintain adequate immunosuppression in kidney transplant recipients. Interestingly, a clinical trial evaluating different treatment strategies to control post-transplant hypertension revealed that losartan (an angiotensin II receptor blocker) significantly decreased the plasma levels of TGF- $\beta 1$ [103].

\section{Non-diabetic Kidney Disease}

In addition to angiotensin receptor blockers, other classes of compounds including angiotensin-converting enzyme inhibitors (ACEIs) and angiotensin receptor blockers (ARBs) have been investigated to target components of the reninangiotensin-aldosterone system (RAAS) in an attempt to reduce kidney fibrosis. Addition of spironolactone (an aldosterone receptor blocker) to a regimen of ARB/ACEI resulted in a decrease in urinary TGF- $\beta 1$ levels in patients with nondiabetic chronic kidney disease [104]. Similarly, a significant reduction in urinary TGF- $\beta 1$ levels was observed in patients with non-diabetic chronic kidney disease after treatment with the ACEI perindopril or the renin inhibitor aliskiren compared to placebo; no significant differences were observed between aliskiren and perindopril treatment [105].

In a randomized controlled trial, patients with adult diffuse proliferative IgA nephropathy were administered either the corticosteroid prednisolone or the antiplatelet dipyridamole [106]. Histological analysis of glomerular biopsies indicated that prednisolone treatment significantly reduced $\alpha$-SMA expression, mesangial cell proliferation, and matrix accumulation, whereas no significant changes were observed in interstitial cellular infiltrates and tubulointerstitial fibrosis.

\section{Other Organs and Syndromes}

\section{Eye}

The scar-preventing activity of anti-TGF- $\beta 2$ monoclonal antibody CAT-152 (lerdelimumab) was tested via a multicentre randomized phase III trial in glaucoma patients undergoing firsttime trabeculectomy [107]. Subconjunctival injections of CAT152 before and after surgery were well-tolerated and did not cause any adverse effects; however, treatment did not reduce intraocular pressure, bleb vascularity, and overall trabeculectomy failure rate compared to placebo. Likewise, presurgery bevacizumab-mediated VEGF targeting failed to reduce collagen deposition and $\alpha$-SMA expression in fibrovascular epiretinal membranes excised via vitrectomy from proliferative diabetic retinopathy patients [108]. Tranilast $(n$-[3,4-anthoranilic acid]) is an anti-allergic drug known to inhibit TGF- $\beta$ signalling and ECM deposition in vitro and in vivo. Topical tranilast administration successfully reduced the progression of mild dry eye in patients with chronic graft versus host disease; the authors suggest that tranilast treatment might achieve this result by reducing fibrotic degeneration of the lacrimal gland and ducts typically associated with the condition [109].

\section{Heart}

Fibrotic remodelling of the myocardium has been associated with increased morbidity and mortality in patients affected by acute myocardial infarction (AMI). A double-blind, placebocontrolled randomized trial was carried out to test the effect of the antioxidant $N$-acetylcysteine (NAC) on TGF- $\beta$ and TNF- $\alpha$ serum levels at 24 and $72 \mathrm{~h}$ post-infarction [110]. While TNF- $\alpha$ levels did not show any variation within and between groups, TGF- $\beta$ levels increased significantly over time within the placebo group, but not in the NAC group. In the same study, higher TGF- $\beta$ levels were reported to correlate with increased MMP-9 levels and reduced left ventricle ejection fraction. 


\section{Dupuytren's Disease}

Palmar fascia biopsies were obtained from Dupuytren's disease patients preoperatively injected with methylprednisolone acetate and untreated patients to assess the antifibrotic potential of steroids [111]. Immunohistochemical assessment indicated that steroid treatment resulted in reduced proliferation (Ki67) of fibroblasts and increased apoptosis (Lewis Y) of macrophages and fibroblasts. Interestingly, flow cytometry indicated that Dupuytren's cells had a tenfold increase in apoptosis rate following steroid treatment in vitro, a response that was not observed in control fascial tissue. These findings suggest that steroid treatment might be a promising strategy to promote apoptosis and reduce proliferation of fascial (myo)fibroblasts in Dupuytren's disease. A different approach to the pharmacological treatment of Dupuytren's disease involves targeting TNF with the monoclonal antibody adalimumab. In a phase II placebo-controlled dose-response study, patients with Dupuytren's disease were randomized to receive different dosages of adalimumab or equivalent volumes of saline [112]. After two weeks from intranodular injection, patients who received the highest dose $(40 \mathrm{mg})$ of adalimumab showed significant reductions in $\alpha$-SMA and procollagen I protein levels, compatible with an inhibition of the myofibroblast phenotype. Interestingly, no changes in mRNA expression were observed for any of the analysed markers between the different treatment groups, indicating that $\alpha$-SMA and procollagen I levels might be predominantly regulated at a post-transcriptional level.

\section{Peyronie's Disease}

Peyronie's disease (PD) is characterized by the formation of scar tissue plaques in the penile tunica albuginea. Phosphodiesterase 5 (PDE5) inhibitors (most frequently tadalafil) have been successfully used to treat PD in a preclinical and clinical context. In a prospective, randomized trial PD patients were administered oral tadalafil, intralesional verapamil (a calcium channel blocker) injections, or a combination of the two over a period of 2 months [113]. The combined treatment resulted in a significant reduction of plaque size and amelioration of clinical symptoms compared to the individual treatment regimes, suggesting that intralesional calcium channel blockers might potentiate the effect of systemic PDE5 inhibitors.

\section{Discussion and Conclusions}

The clinical data collected in this review indicate not only that therapeutic strategies vary greatly between different fibrotic conditions but also that the same strategy might have widely variable efficiency and outcome depending on the nature of the targeted organ. A cogent example is provided by therapies based on IFN- $\gamma$ administration: strikingly, for many of the pathologies in exam (pulmonary fibrosis, bronchiolitis obliterans, keloids, scleroderma, viral hepatitis), different trials show IFN- $\gamma$ to have positive effects, no significant effect, or even detrimental effects on the progression and symptoms of fibrosis. While the efficacy and safety of IFN- $\gamma$ was trialled across a range of pathologic conditions, most therapeutical strategies identified in this study appear to be less "promiscuous" and reflect the different upstream aetiological factors underpinning each condition. It is worth emphasizing that, in the majority of the successful trials evaluated in this review, a direct correlation could be observed between a reduction in myofibroblast differentiation markers (most notably TGF- $\beta 1$ levels, $\alpha$-SMA expression, ECM deposition and remodelling) and improvements in organ functionality and clinical indicators of fibrosis. The next paragraphs summarize the pharmacological approaches that have ameliorated fibrosis symptoms and/or improved organ functionality in patients and attempt to unearth any commonalities between successful therapeutical strategies.

Serum amyloid $\mathrm{P}$ and nintedanib successfully improved pulmonary function in IPF patients, providing evidence that inhibition of fibrocyte proliferation and activity might be a viable therapeutic strategy [114]. Given the role of inflammatory processes in the pathogenesis of asthma, it is not surprising that steroid treatment could be successfully used to supplement standard bronchodilator regimes to ameliorate airway remodelling and fibrosis associated with this condition [115, 116].

Both TGF- $\beta 3$ and bFGF showed good tolerability and significantly reduced scarring in surgical wounds in all the trials analysed in this review, suggesting that topical administration of antifibrotic cytokines is a promising approach to limiting hypertrophic scarring associated with surgical procedures. Paradoxically, while the in vivo antifibrotic activity of TGF- $\beta 3$ has been demonstrated in both preclinical and clinical settings, the cytokine has been shown to induce $\alpha$-SMA expression in vitro and collagen deposition in vivo, indicating that further research might be necessary to prevent unwanted side effects [48]. It is worth emphasizing that while the phase I/II trials discussed in this review indicate that TGF- $\beta 3$ could successfully minimize surgical wound scarring, it failed to achieve the phase III trial endpoints in a successive trial, the results of which were not subsequently published in a peerreviewed academic journal [117].

Improvements of clinical symptoms in patients with localized or systemic sclerosis were obtained via pharmacological inhibition of Wnt (pirfenidone, rituximab) and TGF- $\beta / \mathrm{Smad}$ (fresolimumab, nilotinib) signalling, confirming preclinical observations of the synergistic effect of the two pathways in the pathogenesis of skin fibrotic disorders [118, 119]. 
Due to their established activity as both antiviral and antifibrotic agents, interferons have been widely investigated as therapeutic agents for the treatment of viral hepatitis and prevention of the associated liver fibrosis. Interestingly, three different clinical trials highlighted that while IFN- $\gamma$ was unable to reduce HBV and HCV load, it was successful in reducing myofibroblast presence and fibrosis score in patients with chronic viral hepatitis. Conversely, data from other clinical trials seems to indicate that while treatment with IFN- $\gamma$ may not be sufficient to ameliorate liver fibrosis symptoms on its own, it does seem to potentiate the effect of ACE inhibitors and AT1 antagonists. A substantial body of literature exists regarding the use of $\mathrm{CHM}$ remedies to treat chronic viral hepatitis [120]. The current review identified two such clinical trials in which, respectively, salvianolic acid-B and ginseng extract were successful in reducing fibrosis markers in patients with chronic HBV infection. In two further clinical trials, hepatic fibrosis symptoms were improved by treating NASH patients with, respectively, vitamin E and pegbelfermin.

Five of the identified trials investigated strategies to ameliorate or eliminate CNI-induced fibrosis in kidney allograft recipients. In all but one of the studies, withdrawal from a CNI-based immunosuppressive regime resulted in a reduction in kidney fibrosis markers; these results corroborate the burgeoning body of evidence pointing to the necessity of devising alternative immunosuppressive strategies to the routinely used tacrolimus and cyclosporine regimes [121]. Pharmacological targeting of different RAAS components resulted in a reduction of TGF- $\beta 1$ levels in patients with nondiabetic kidney disease, whereas prednisone reduced $\alpha$-SMA expression but failed to ameliorate tubulointerstitial fibrosis in patients with diffuse proliferative IgA nephropathy.

Inhibition of TGF- $\beta$ signalling is a promising strategy to prevent scarring following eye surgery. Interestingly, while anti-TGF- $\beta 2$ monoclonal antibodies failed to reduce intraocular pressure and ultimately trabeculectomy failure ratio, broad-spectrum TGF- $\beta$ inhibition via tranilast successfully reduced the progression of mild dry eye in chronic GVHD patients. These observations indicate that given the profibrotic nature of both TGF- $\beta 1$ and $\beta 2$ and their action through a shared set of receptors, strategies aimed at blocking TGF- $\beta$ receptors (as is the case for tranilast) might be more effective than targeting the growth factors themselves [122, 123].

Surgical approaches such as open fasciectomy and percutaneous needle aponeurotomy are currently the gold standard for the treatment of Dupuytren's disease [124]. However, the clinical data evaluated in the present review highlight that anti-inflammatory strategies such as steroid treatment and TNF- $\alpha$ signalling inhibition might successfully reduce myofibroblast persistence and activity, making it a promising approach to complement (or potentially replace) the need for surgical procedures. Similarly, while surgery is still considered the gold standard for the treatment of Peyronie's disease, an increasing body of research investigates non-surgical alternatives to its management [125]. Clinical data analysed in this review indicate that the combined use of tadalafil and verapamil significantly ameliorated clinical symptoms in PD patients. As verapamil had previously been show to also potentiate collagenase activity in PD plaques, further clinical investigation would be beneficial to investigate whether the combined administration of PDE5 inhibitors, calcium channel blockers, and collagenase might be a viable strategy for the non-surgical treatment of PD [126, 127].

Despite abundant preclinical evidence supporting the antifibrotic activity of interleukin-1, none of the trials identified in this review evaluated its effect in a clinical context. A simple explanation of this observation could be the welldocumented proinflammatory effect of this cytokine, which might result in the onset of unwanted side effects; unsurprisingly, a wealth of clinical research is focused on the inhibition, rather than promotion, of IL-1 activity [128]. While systemic administration of IL-1 should not be considered a viable treatment strategy, further research is required to assess whether its potential antifibrotic activity might outweigh the risk of side effects when administered topically.

This review consolidates the notion that, despite the similarities in cellular and molecular mechanisms underlying fibrotic degeneration in different organs, there is currently no "one size fits all" approach towards its pharmacological treatment. Moreover, said mechanisms often show a pleiotropic regulatory action during the onset and progression of fibrosis. This, together with the presence of positive feedback loops, makes it difficult (if at all possible) to precisely pinpoint which phase of the process is being targeted by each treatment. However, the present study indicates that the systematic evaluation of clinical data can unearth trends and connections between approaches used to successfully treat different fibrotic pathologies, informing and facilitating the future design of therapeutical strategies specific for each condition. Due to space constraints, the search strategy utilized in this review was limited to (and by) the use of only four cytokines as proxies of myofibroblast activity, as they had previously been identified as the most well-established myofibroblastrepressing factors. Future studies might be required to expand on the present investigation by focusing on other molecules that have shown anti-fibrotic potential in a preclinical setting.

Acknowledgements The author wishes to thank Dr. Alfonso Siani for his precious advice towards the development of this manuscript.

\section{Compliance with Ethical Standards}

Conflict of Interest The author declares that he has no conflict of interest.

Ethical Approval Not applicable: this is a literature-based study which did not involve animals, human participants, nor human tissues. 
Informed Consent Not applicable: this study did not involve human participants.

Open Access This article is licensed under a Creative Commons Attribution 4.0 International License, which permits use, sharing, adaptation, distribution and reproduction in any medium or format, as long as you give appropriate credit to the original author(s) and the source, provide a link to the Creative Commons licence, and indicate if changes were made. The images or other third party material in this article are included in the article's Creative Commons licence, unless indicated otherwise in a credit line to the material. If material is not included in the article's Creative Commons licence and your intended use is not permitted by statutory regulation or exceeds the permitted use, you will need to obtain permission directly from the copyright holder. To view a copy of this licence, visit http://creativecommons.org/licenses/by/4.0/.

\section{References}

1. Walraven M, Hinz B. Therapeutic approaches to control tissue repair and fibrosis: extracellular matrix as a game changer. Matrix Biol. 2018;71-72:205-24. https://doi.org/10.1016/j. matbio.2018.02.020.

2. Elson EL, Qian H, Fee JA, Wakatsuki T. A model for positive feedback control of the transformation of fibroblasts to myofibroblasts. Prog Biophys Mol Biol. 2018; 144:30-40. https://doi.org/10.1016/j.pbiomolbio.2018.08.004.

3. Yazdani S, Bansal R, Prakash J. Drug targeting to myofibroblasts: implications for fibrosis and cancer. Adv Drug Deliv Rev. 2017;121:101-16. https://doi.org/10.1016/j.addr.2017.07.010.

4. Hinz B. Myofibroblasts. Exp Eye Res. 2016;142:56-70. https:// doi.org/10.1016/j.exer.2015.07.009.

5. Bochaton-Piallat M-L, Gabbiani G, Hinz B. The myofibroblast in wound healing and fibrosis: answered and unanswered questions. F1000Res. 2016;5:F1000 Faculty Rev-752. https://doi.org/10. 12688/f1000research.8190.1.

6. Gabbiani G, Ryan G, Majno G. Presence of modified fibroblasts in granulation tissue and their possible role in wound contraction. Experientia. 1971;27(5):549-50.

7. Carrel A, Hartmann A. Cicatrization of wounds: i. The relation between the size of a wound and the rate of its cicatrization. J Exp Med. 1916;24(5):429-50. https://doi.org/10.1084/jem.24.5.429.

8. Tomasek JJ, Gabbiani G, Hinz B, Chaponnier C, Brown RA. Myofibroblasts and mechano-regulation of connective tissue remodelling. Nat Rev Mol Cell Biol. 2002;3(5):349-363.

9. Serini G, Gabbiani G. Mechanisms of myofibroblast activity and phenotypic modulation. Exp Cell Res. 1999;250(2):273-283.

10. Skalli O, Ropraz P, Trzeciak A, Benzonana G, Gillessen D, Gabbiani G. A monoclonal antibody against alpha-smooth muscle actin: a new probe for smooth muscle differentiation. J Cell Biol. 1986;103(6 Pt 2):2787-96.

11. Hinz B, Wehrle-Haller B, Chaponnier C, Dugina V, Ballestrem C. $\alpha$-Smooth muscle actin is crucial for focal adhesion maturation in myofibroblasts. Mol Biol Cell. 2003;14(6):2508-19. https://doi. org/10.1091/mbc.E02-11-0729.

12. Dugina V, Fontao L, Chaponnier C, Vasiliev J, Gabbiani G. Focal adhesion features during myofibroblastic differentiation are controlled by intracellular and extracellular factors. J Cell Sci. 2001;114(18):3285--3296.

13. Klingberg F, Hinz B, White ES. The myofibroblast matrix: implications for tissue repair and fibrosis. J Pathol. 2013;229(2):298309 .
14. Darby IA, Zakuan N, Billet F, Desmoulière A. The myofibroblast, a key cell in normal and pathological tissue repair. Cell Mol Life Sci. 2016;6:1145.

15. Giannandrea M, Parks WC. Diverse functions of matrix metalloproteinases during fibrosis. Dis Model Mech. 2014;2:193-203. https://doi.org/10.1242/dmm.012062.

16. Darby IA, Laverdet B, Bonté F, Desmouliere A. Fibroblasts and myofibroblasts in wound healing. Clin Cosmet Investig Dermatol. 2014;7:301.

17. Hinz B, Phan SH, Thannickal VJ, Galli A, Bochaton-Piallat M-L, Gabbiani G. The Myofibroblast: one function, multiple origins. Am J Pathol. 2007;170(6):1807-16. https://doi.org/10.2353/ ajpath.2007.070112.

18. McAnulty RJ. Fibroblasts and myofibroblasts: their source, function and role in disease. Int J Biochem Cell Biol. 2007;39(4):66671. https://doi.org/10.1016/j.biocel.2006.11.005.

19. Rajkumar VS, Howell K, Csiszar K, Denton CP, Black CM, Abraham DJ. Shared expression of phenotypic markers in systemic sclerosis indicates a convergence of pericytes and fibroblasts to a myofibroblast lineage in fibrosis. Arthritis Res Ther. 2005;7(5): R1113-23. https://doi.org/10.1186/ar1790.

20. Yang X, Chen B, Liu T, Chen X. Reversal of myofibroblast differentiation: a review. Eur J Pharmacol. 2014;734:83-90. https:// doi.org/10.1016/j.ejphar.2014.04.007.

21. Cruz-Solbes AS, Youker K. Epithelial to mesenchymal transition (EMT) and endothelial to mesenchymal transition (EndMT): role and implications in kidney fibrosis. Results Probl Cell Differ. 2017;60:345-72. https://doi.org/10.1007/978-3-319-51436-9 13.

22. Hinz B, Phan SH, Thannickal VJ, Prunotto M, Desmoulière A, Varga J, et al. Recent developments in myofibroblast biology: paradigms for connective tissue remodeling. Am J Pathol. 2012;180(4):1340-55. https://doi.org/10.1016/j.ajpath.2012.02. 004.

23. Siani A, Tirelli N. Myofibroblast differentiation: main features, biomedical relevance, and the role of reactive oxygen species. Antioxid Redox Signal. 2014;21(5):768-85. https://doi.org/10. 1089/ars.2013.5724.

24. Hinz B. The myofibroblast: paradigm for a mechanically active cell. J Biomech. 2010;43(1):146-55. https://doi.org/10.1016/j. jbiomech.2009.09.020.

25. Hinz B. Tissue stiffness, latent TGF- $\beta 1$ activation, and mechanical signal transduction: implications for the pathogenesis and treatment of fibrosis. Curr Rheumatol Rep. 2009;11(2):120-6. https:// doi.org/10.1007/s11926-009-0017-1.

26. Zhao XH, Laschinger C, McCulloch CA, Arora P, Szászi K, Kapus A. Force activates smooth muscle $\alpha$-actin promoter activity through the Rho signaling pathway. J Cell Sci. 2007;120(10): 1801-9. https://doi.org/10.1242/jcs.001586.

27. Akasaka Y, Ono I, Tominaga A, Ishikawa Y, Ito K, Suzuki T, et al. Basic fibroblast growth factor in an artificial dermis promotes apoptosis and inhibits expression of $\alpha$-smooth muscle actin, leading to reduction of wound contraction. Wound Repair Regen. 2007;15(3):378-89. https://doi.org/10.1111/j.1524-475X.2007. 00240.x.

28. Cushing MC, Mariner PD, Liao JT, Sims EA, Anseth KS. Fibroblast growth factor represses Smad-mediated myofibroblast activation in aortic valvular interstitial cells. FASEB J. 2008;22(6):1769-77. https://doi.org/10.1096/fj.07-087627.

29. Khouw I, van Wachem PB, Plantinga JA, Vujaskovic Z, MJB W, de Leij L, et al. TGF-beta and bFGF affect the differentiation of proliferating porcine fibroblasts into myofibroblasts in vitro. Biomaterials. 1999;20(19):1815-22.

30. Hata Y, Ishikawa H, Ueki T, Kajii TS, Tamaoki S, Tsuruga E, et al. Quantitative evaluation of myofibroblast apoptosis during wound healing in rat palate after post-operative administration of basic 
fibroblast growth factor (bFGF). Acta Odontol Scand. 2013;71(6): 1501-7. https://doi.org/10.3109/00016357.2013.773370.

31. Desai VD, Hsia HC, Schwarzbauer JE. Reversible modulation of myofibroblast differentiation in adipose-derived mesenchymal stem cells. PLoS One. 2014;9(1):1-12. https://doi.org/10.1371/ journal.pone. 0086865 .

32. Huang C, Orbay H, Tobita M, Miyamoto M, Tabata Y, Hyakusoku $\mathrm{H}$, et al. Proapoptotic effect of control-released basic fibroblast growth factor on skin wound healing in a diabetic mouse model. Wound Repair Regen. 2016;24(1):65-74. https://doi.org/10.1111/ wrr. 12375 .

33. Wang Y, Zhao C, Yu W, Shen C, Wang W, Zhao Y, et al. Predictive value of serum IFN- $\gamma$ inducible protein-10 and IFN- $\gamma /$ IL-4 ratio for liver fibrosis progression in CHB patients. Sci Rep. 2017;11(1):S900-S1.

34. Svystonyuk DA, Ngu JM, Mewhort HE, Lipon BD, Teng G, Guzzardi DG, et al. Fibroblast growth factor-2 regulates human cardiac myofibroblast-mediated extracellular matrix remodeling. J Transl Med. 2015;13(1):147.

35. Moulin V, Castilloux G, Auger FA, Garrel D, O'Connor-McCourt $\mathrm{MD}$, Germain L. Modulated response to cytokines of human wound healing myofibroblasts compared to dermal fibroblasts. Exp Cell Res. 1998;238(1):283-93. https://doi.org/10.1006/excr. 1997.3827.

36. Oldroyd SD, Thomas GL, Gabbiani G, El Nahas AM. Interferon$\gamma$ inhibits experimental renal fibrosis. Kidney Int. 1999;56(6): 2116-27.

37. Rockey DC, Housset CN, Friedman SL. Activation-dependent contractility of rat hepatic lipocytes in culture and in vivo. J Clin Invest. 1993;92(4):1795-804. https://doi.org/10.1172/JCI116769.

38. Hong S, Manna Z, Minuk GY, Yuewen G. Different effects of rat interferon alpha, beta and gamma on rat hepatic stellate cell proliferation and activation. BMC Cell Biol. 2002;3:9-8. https://doi. org/10.1186/1471-2121-3-9.

39. Shen H, Yao P, Lee E, Greenhalgh D, Soulika AM. Interferongamma inhibits healing post scald burn injury. Wound Repair Regen. 2012;20(4):580-91. https://doi.org/10.1111/j.1524-475X. 2012.00812.x.

40. Cornelissen AMH, Maltha JC, Von den Hoff JW, KuijpersJagtman AM. Local injection of IFN-gamma reduces the number of myofibroblasts and the collagen content in palatal wounds IFNgamma may be a promising pharmaceutical agent to reduce wound contraction and scarring after cleft palate surgery. J Dent Res. 2000;79(10):1782.

41. Sobral LM, Montan PF, Martelli-Junior H, Graner E, Coletta RD. Opposite effects of TGF-betal and IFN-gamma on transdifferentiation of myofibroblast in human gingival cell cultures. J Clin Periodontol. 2007;34(5):397-406.

42. Tanaka K, Sano K, Yuba K, Katsumura K, Nakano T, Kobayashi $\mathrm{M}$, et al. Inhibition of induction of myofibroblasts by interferon gamma in a human fibroblast cell line. Int Immunopharmacol. 2003;3(9):1273-80.

43. Yokozeki M, Baba Y, Shimokawa H, Moriyama K, Kuroda T. Interferon-gamma inhibits the myofibroblastic phenotype of rat palatal fibroblasts induced by transforming growth factor-beta1 in vitro. FEBS Lett. 1999;442(1):61-4.

44. Gu L, Zhu Y-j, Guo Z-j, Xu X-x, Xu W-b. Effect of IFN-gamma and dexamethasone on TGF-beta1-induced human fetal lung fibroblast-myofibroblast differentiation. Acta Pharmacol Sin. 2004;25(11):1479-88.

45. Poosti F, Bansal R, Yazdani S, Prakash J, Post E, Klok P, et al. Selective delivery of IFN-gamma to renal interstitial myofibroblasts: a novel strategy for the treatment of renal fibrosis. FASEB J. 2015;29(3):1029-42. https://doi.org/10.1096/fj.14258459 .
46. Bansal R, Post E, Proost JH, de Jager-Krikken A, Poelstra K, Prakash J. PEGylation improves pharmacokinetic profile, liver uptake and efficacy of interferon gamma in liver fibrosis. $\mathrm{J}$ Control Release. 2011;154(3):233-40. https://doi.org/10.1016/j. jconrel.2011.05.027.

47. Foster W, Li Y, Usas A, Somogyi G, Huard J. Gamma interferon as an antifibrosis agent in skeletal muscle. J Orthop Res. 2003;21(5):798-804. https://doi.org/10.1016/S0736-0266(03) 00059-7.

48. Serini G, Gabbiani G. Modulation of $\alpha$-smooth muscle actin expression in fibroblasts by transforming growth factor- $\beta$ isoforms: an in vivo and in vitro study. Wound Repair Regen. 1996;4(2): 278-87.

49. Shah M, Foreman DM, Ferguson MWJ. Neutralization of tgf-beta(1) and tgf-beta(2) or exogenous addition of tgf-beta(3) to cutaneous rat wounds reduces scarring. J Cell Sci. 1995;108(3):9851002.

50. Karamichos D, Hutcheon AEK, Zieske JD. Reversal of fibrosis by TGF- $\beta 3$ in a 3D in vitro model. Exp Eye Res. 2014;124:31-6. https://doi.org/10.1016/j.exer.2014.04.020.

51. Waddington SN, Crossley R, Sheard V, Howe SJ, Buckley SMK, Coughlan L, et al. Gene delivery of a mutant TGF $\beta 3$ reduces markers of scar tissue formation after cutaneous wounding. Mol Ther. 2010;18(12):2104-11. https://doi.org/10.1038/mt.2010.174.

52. Hosokawa R, Nonaka K, Morifuji M, Ohishi M, Shum L. TGF- $\beta 3$ decreases type I collagen and scarring after labioplasty. J Dent Res. 2003;82(7):558-64. https://doi.org/10.1177/154405910308200714.

53. Wu Y, Yuan X, Li H, Wang Y, Yang L, Huang S, et al. Mesenchymal stem cells suppress fibroblast proliferation and reduce skin fibrosis through a TGF- $\beta 3$-dependent activation. Int $\mathrm{J}$ Low Extrem Wounds. 2015;14(1):50-62. https://doi.org/10.1177/ 1534734614568373.

54. Shephard P, Martin G, Smola-Hess S, Brunner G, Krieg T, Smola $\mathrm{H}$. Myofibroblast differentiation is induced in keratinocytefibroblast co-cultures and is antagonistically regulated by endogenous transforming growth factor- $\beta$ and Interleukin-1. Am J Pathol. 2004;164(6):2055-66. https://doi.org/10.1016/S00029440(10)63764-9.

55. Barbosa FL, Chaurasia SS, Kaur H, de Medeiros FW, Agrawal V, Wilson SE. Stromal interleukin-1 expression in the cornea after haze-associated injury. Exp Eye Res. 2010;91(3):456-61. https:// doi.org/10.1016/j.exer.2010.06.023.

56. Kaur H, Chaurasia SS, Agrawal V, Suto C, Wilson SE. Corneal myofibroblast viability: opposing effects of IL-1 and TGF beta1. Exp Eye Res. 2009;89(2):152-8. https://doi.org/10.1016/j.exer. 2009.03.001.

57. Mia MM, Boersema M, Bank RA. Interleukin- $1 \beta$ attenuates myofibroblast formation and extracellular matrix production in dermal and lung fibroblasts exposed to transforming growth factor- $\beta 1$. PLoS One. 2014;9(3):1-19. https://doi.org/10.1371/ journal.pone.0091559.

58. Zhang HY, Phan SH. Inhibition of myofibroblast apoptosis by transforming growth factor beta(1). Am J Respir Cell Mol Biol. 1999;21(6):658-65. https://doi.org/10.1165/ajrcmb.21.6.3720.

59. Ziesche R, Hofbauer E, Wittmann K, Petkov V, Block LH. A preliminary study of long-term treatment with interferon gamma$1 \mathrm{~b}$ and low-dose prednisolone in patients with idiopathic pulmonary fibrosis. N Engl J Med. 1999;341(17):1264-9. https://doi. org/10.1056/nejm199910213411703.

60. Strieter RM, Starko KM, Enelow RI, Noth I, Valentine VG. Effects of interferon-gamma $1 \mathrm{~b}$ on biomarker expression in patients with idiopathic pulmonary fibrosis. Am J Respir Crit Care Med. 2004;170(2):133-40. https://doi.org/10.1164/rccm.2003121670OC.

61. Diaz KT, Skaria S, Harris K, Solomita M, Lau S, Bauer K, et al. Delivery and safety of inhaled interferon-gamma in idiopathic 
pulmonary fibrosis. J Aerosol Med Pulm Drug Deliv. 2012;25(2): 79-87. https://doi.org/10.1089/jamp.2011.0919.

62. Tzortzaki EG, Antoniou KM, Zervou MI, Lambiri I, Koutsopoulos A, Tzanakis N, et al. Effects of antifibrotic agents on TGF-beta1, CTGF and IFN-gamma expression in patients with idiopathic pulmonary fibrosis. Respir Med. 2007;101(8): 1821-9. https://doi.org/10.1016/j.rmed.2007.02.006.

63. Raghu G, Brown KK, Bradford WZ, Starko K, Noble PW, Schwartz DA, et al. A placebo-controlled trial of interferon gamma-1b in patients with idiopathic pulmonary fibrosis. $\mathrm{N}$ Engl J Med. 2004;350(2):125-33. https://doi.org/10.1056/ NEJMoa030511.

64. King TE, Albera C, Bradford WZ, Costabel U, Hormel P, Lancaster L, et al. Effect of interferon gamma-1b on survival in patients with idiopathic pulmonary fibrosis (INSPIRE): a multicentre, randomised, placebo-controlled trial. Lancet. 2009;374(9685):222-8.

65. Richeldi L, Du Bois R, Raghu G, Azuma A, Brown KK, Costabel $\mathrm{U}$, et al. Efficacy and safety of nintedanib in patients with idiopathic pulmonary fibrosis: results of two 52-week, phase III, randomized, placebo-controlled trials (INPULSISTM). Lancet Respir Med. 2014;189.

66. Raghu G, Richeldi L, Crestani B, Wung P, Bejuit R, Esperet C, et al. SAR156597 in idiopathic pulmonary fibrosis: a phase 2 placebo-controlled study (DRI11772). Eur Respir J. 2018;52(6): 1801130.

67. Dillingh MR, van den Blink B, Moerland M, van Dongen MG, Levi M, Kleinjan A, et al. Recombinant human serum amyloid $\mathrm{P}$ in healthy volunteers and patients with pulmonary fibrosis. Pulm Pharmacol Ther. 2013;26(6):672-6. https://doi.org/10.1016/j. pupt.2013.01.008.

68. Raghu G, van den Blink B, Hamblin MJ, Brown AW, Golden JA, Ho LA, et al. Effect of recombinant human pentraxin 2 vs placebo on change in forced vital capacity in patients with idiopathic pulmonary fibrosis: a randomized clinical trial. JAMA. 2018;319(22):2299-307. https://doi.org/10.1001/jama.2018. 6129 .

69. Hoshino M, Takahashi M, Takai Y, Sim J. Inhaled corticosteroids decrease subepithelial collagen deposition by modulation of the balance between matrix metalloproteinase- 9 and tissue inhibitor of metalloproteinase-1 expression in asthma. J Allergy Clin Immunol. 1999;104(2 Pt 1):356-63.

70. Kelly MM, O'Connor TM, Leigh R, Otis J, Gwozd C, Gauvreau $\mathrm{GM}$, et al. Effects of budesonide and formoterol on allergeninduced airway responses, inflammation, and airway remodeling in asthma. J Allergy Clin Immunol. 2010;125(2):349-56.e13. https://doi.org/10.1016/j.jaci.2009.09.011.

71. Kelly MM, Chakir J, Vethanayagam D, Boulet LP, Laviolette M, Gauldie J, et al. Montelukast treatment attenuates the increase in myofibroblasts following low-dose allergen challenge. Chest. 2006;130(3):741-53. https://doi.org/10.1378/chest.130.3.741.

72. Moss RB, Mayer-Hamblett N, Wagener J, Daines C, Hale K, Ahrens R, et al. Randomized, double-blind, placebo-controlled, dose-escalating study of aerosolized interferon gamma- $1 \mathrm{~b}$ in patients with mild to moderate cystic fibrosis lung disease. Pediatr Pulmonol. 2005;39(3):209-18. https://doi.org/10.1002/ppul. 20152.

73. Panahi Y, Ghanei M, Aslani J, Mojtahedzadeh M. The therapeutic effect of gamma interferon in chronic bronchiolitis due to mustard gas. Iran J Allergy Asthma Immunol. 2005;4(2):83-90.

74. Zheng L, Walters EH, Wang N, Whitford H, Orsida B, Levvey B, et al. Effect of inhaled fluticasone propionate on BAL TGF-beta(1) and bFGF concentrations in clinically stable lung transplant recipients. J Heart Lung Transplant. 2004;23(4):446-55.

75. Ferguson MW, Duncan J, Bond J, Bush J, Durani P, So K, et al. Prophylactic administration of avotermin for improvement of skin scarring: three double-blind, placebo-controlled, phase I/II studies. Lancet. 2009;373(9671):1264-74. https://doi.org/10.1016/s01406736(09)60322-6.

76. Bush J, Duncan JA, Bond JS, Durani P, So K, Mason T, et al. Scarimproving efficacy of avotermin administered into the wound margins of skin incisions as evaluated by a randomized, double-blind, placebo-controlled, phase II clinical trial. Plast Reconstr Surg. 2010;126(5):1604-15. https://doi.org/10.1097/PRS. 0b013e3181ef8e66.

77. McCollum PT, Bush JA, James G, Mason T, O'Kane S, McCollum C, et al. Randomized phase II clinical trial of avotermin versus placebo for scar improvement. Br J Surg. 2011;98(7):925-34. https://doi.org/10.1002/bjs.7438.

78. So K, McGrouther DA, Bush JA, Durani P, Taylor L, Skotny G, et al. Avotermin for scar improvement following scar revision surgery: a randomized, double-blind, within-patient, placebo-controlled, phase II clinical trial. Plast Reconstr Surg. 2011;128(1): 163-72. https://doi.org/10.1097/PRS.0b013e318217429b.

79. Akita S, Akino K, Yakabe A, Tanaka K, Anraku K, Yano H, et al. Basic fibroblast growth factor is beneficial for postoperative color uniformity in split-thickness skin grafting. Wound Repair Regen. 2010;18(6):560-6. https://doi.org/10.1111/j.1524-475X.2010. 00620.x.

80. Hayashida K, Akita S. Quality of pediatric second-degree burn wound scars following the application of basic fibroblast growth factor: results of a randomized, controlled pilot study. Ostomy Wound Manage. 2012;58(8):32-6.

81. Granstein RD, Rook A, Flotte TJ, Haas A, Gallo RL, Jaffe HS, et al. A controlled trial of intralesional recombinant interferongamma in the treatment of keloidal scarring. Clinical and histologic findings. Arch Dermatol. 1990;126(10):1295-302.

82. Broker BJ, Rosen D, Amsberry J, Schmidt R, Sailor L, Pribitkin EA, et al. Keloid excision and recurrence prophylaxis via intradermal interferon-gamma injections: a pilot study. Laryngoscope. 1996;106(12 Pt 1):1497-501.

83. Hunzelmann N, Anders S, Fierlbeck G, Hein R, Herrmann K, Albrecht M, et al. Double-blind, placebo-controlled study of intralesional interferon gamma for the treatment of localized scleroderma. J Am Acad Dermatol. 1997;36(3 Pt 1):433-5.

84. Rodriguez-Castellanos M, Tlacuilo-Parra A, Sanchez-Enriquez S, Velez-Gomez E, Guevara-Gutierrez E. Pirfenidone gel in patients with localized scleroderma: a phase II study. Arthritis Res Ther. 2015; 16 .

85. Gordon JK, Martyanov V, Magro C, Wildman HF, Wood TA, Huang WT, et al. Nilotinib (TasignaTM) in the treatment of early diffuse systemic sclerosis: an open-label, pilot clinical trial. Arthritis Res Ther. 2015;17:213.

86. Daoussis D, Tsamandas A, Antonopoulos I, Filippopoulou A, Papachristou DJ, Papachristou NI, et al. B cell depletion therapy upregulates Dkk-1 skin expression in patients with systemic sclerosis: association with enhanced resolution of skin fibrosis. Arthritis Res Ther. 2016;18(1):118.

87. Rice LM, Padilla CM, McLaughlin SR, Mathes A, Ziemek J, Goummih S, et al. Fresolimumab treatment decreases biomarkers and improves clinical symptoms in systemic sclerosis patients. J Clin Invest. 2015;125(7):2795-807. https://doi.org/10.1172/ jci77958.

88. Papp G, Horvath IF, Barath S, Gyimesi E, Vegh J, Szodoray P, et al. Immunomodulatory effects of extracorporeal photochemotherapy in systemic sclerosis. Clin Immunol. 2012;142(2):150-9.

89. Weng HL, Wang BE, Jia JD, Wu WF, Xian JZ, Mertens PR, et al. Effect of interferon-gamma on hepatic fibrosis in chronic hepatitis B virus infection: a randomized controlled study. Clin Gastroenterol Hepatol. 2005;3(8):819-28. 
90. Muir AJ, Sylvestre PB, Rockey DC. Interferon gamma-1b for the treatment of fibrosis in chronic hepatitis C infection. J Viral Hepat. 2006;13(5):322-8. https://doi.org/10.1111/j.1365-2893.2005. 00689.x.

91. Yoshiji H, Noguchi R, Kojima H, Ikenaka Y, Kitade M, Kaji K, et al. Interferon augments the anti-fibrotic activity of an angiotensin-converting enzyme inhibitor in patients with refractory chronic hepatitis C. World J Gastroenterol. 2006;12(42):678691.

92. Pockros PJ, Jeffers L, Afdhal N, Goodman ZD, Nelson D, Gish RG, et al. Final results of a double-blind, placebo-controlled trial of the antifibrotic efficacy of interferon-gammalb in chronic hepatitis $\mathrm{C}$ patients with advanced fibrosis or cirrhosis. Hepatology. 2007;45(3):569-78. https://doi.org/10.1002/hep.21561.

93. El-Sisi AE, Elfert AA, El-Sayad M, Zakaria S. A randomized controlled study of the effect of AT1 antagonist on fibrosis markers in HCV Egyptian patients. J Gastroenterol Hepatol Res. 2012;1(9):217-22.

94. Liu P, Hu YY, Liu C, Zhu DY, Xue HM, Xu ZQ, et al. Clinical observation of salvianolic acid B in treatment of liver fibrosis in chronic hepatitis B. World J Gastroenterol. 2002;8(4):679-85.

95. Choi SH, Yang KJ, Lee DS. Effects of complementary combination therapy of Korean red ginseng and antiviral agents in chronic hepatitis B. J Altern Complement Med. 2016;22(12):964-9.

96. Sanyal AJ, Chalasani N, Kowdley KV, McCullough A, Diehl AM, Bass NM, et al. Pioglitazone, vitamin E, or placebo for nonalcoholic steatohepatitis. N Engl J Med. 2010;362(18):1675-85. https://doi.org/10.1056/NEJMoa0907929.

97. Guy CD, Suzuki A, Abdelmalek MF, Burchette JL, Diehl AM, Nash CRN. Treatment response in the PIVENS trial is associated with decreased Hedgehog pathway activity. Hepatology. 2015;61(1):98-107. https://doi.org/10.1002/hep.27235.

98. Sanyal A, Charles ED, Neuschwander-Tetri BA, Loomba R, Harrison SA, Abdelmalek MF, et al. Pegbelfermin (BMS986036), a PEGylated fibroblast growth factor 21 analogue, in patients with non-alcoholic steatohepatitis: a randomised, double-blind, placebo-controlled, phase $2 \mathrm{a}$ trial. Lancet. 2019;392(10165):2705-17.

99. Bicknell GR, Williams ST, Shaw JA, Pringle JH, Furness PN, Nicholson ML. Differential effects of cyclosporin and tacrolimus on the expression of fibrosis-associated genes in isolated glomeruli from renal transplants. Br J Surg. 2000;87(11):1569-75.

100. Rivelli RF, Goncalves RT, Leite M, Santos MAR, Delgado AG, Cardoso LR, et al. Early withdrawal of calcineurin inhibitor from a sirolimus-based immunosuppression stabilizes fibrosis and the transforming growth factor-beta signalling pathway in kidney transplant. Nephrology. 2015;20(3):168-76. https://doi.org/10. 1111/nep.12368.

101. Baczkowska T, Perkowska-Ptasińska A, Sadowska A, Lewandowski Z, Nowacka-Cieciura E, Cieciura T, et al. Serum TGF-beta1 correlates with chronic histopathological lesions in protocol biopsies of kidney allograft recipients. Transplant Proc. 2005;37(2):773-5.

102. Rostaing L, Hertig A, Albano L, Anglicheau D, Durrbach A, Vuiblet V, et al. Fibrosis progression according to epithelialmesenchymal transition profile: a randomized trial of everolimus versus CsA. Am J Transplant. 2015;15(5):1303-12. https://doi. org/10.1111/ajt.13132.

103. el-Agroudy AE, Hassan NA, Foda MA, Ismail AM, el-Sawy EA, Mousa $\mathrm{O}$, et al. Effect of angiotensin II receptor blocker on plasma levels of TGF-beta 1 and interstitial fibrosis in hypertensive kidney transplant patients. Am J Nephrol. 2003;23(5):300-6.

104. Guney I, Selcuk NY, Altintepe L, Atalay H, Basarali MK, Büyükbaş S. Antifibrotic effects of aldosterone receptor blocker (spironolactone) in patients with chronic kidney disease. Ren Fail. 2009;31(9):779-84.
105. Lizakowski S, Tylicki L, Renke M, Rutkowski P, Heleniak Z, Slawinska-Morawska M, et al. Aliskiren and perindopril reduce the levels of transforming growth factor-beta in patients with nondiabetic kidney disease. Am J Hypertens. 2012;25(6):636-9.

106. Shoji T, Nakanishi I, Suzuki A, Hayashi T, Togawa M, Okada N, et al. Early treatment with corticosteroids ameliorates proteinuria, proliferative lesions, and mesangial phenotypic modulation in adult diffuse proliferative IgA nephropathy. Am J Kidney Dis. 2000;35(2):194-201.

107. Khaw P, Grehn F, Holló G, Overton B, Wilson R, Vogel R, et al. A phase III study of subconjunctival human anti-transforming growth factor beta(2) monoclonal antibody (CAT-152) to prevent scarring after first-time trabeculectomy. Ophthalmology. 2007;114(10):1822-30.

108. Jiao C, Eliott D, Spee C, He S, Wang K, Mullins RF, et al. Apoptosis and angiofibrosis in diabetic tractional membranes after vascular endothelial growth factor inhibition: results of a prospective trial. Report no. 2. Retina. 2019;39(2):265-73. https://doi.org/ 10.1097/IAE.0000000000001952.

109. Ogawa Y, Dogru M, Uchino M, Tatematsu Y, Kamoi M, Yamamoto Y, et al. Topical tranilast for treatment of the early stage of mild dry eye associated with chronic GVHD. Bone Marrow Transplant. 2010;45(3):565-9.

110. Talasaz AH, Khalili H, Jenab Y, Salarifar M, Broumand MA, Darabi F. N-Acetylcysteine effects on transforming growth factor- $\beta$ and tumor necrosis factor- $\alpha$ serum levels as pro-fibrotic and inflammatory biomarkers in patients following ST-segment elevation myocardial infarction. Drugs R D. 2013;13(3):199-205.

111. Meek RMD, McLellan S, Reilly J, Crossan JF. The effect of steroids on Dupuytren's disease: role of programmed cell death. J Hand Surg Br. 2002;27 B(3):270-3. https://doi.org/10.1054/jhsb. 2001.0742

112. Nanchahal J, Ball C, Davidson D, Williams L, Sones W, McCann FE, et al. Anti-tumour necrosis factor therapy for Dupuytren's disease: a randomised dose response proof of concept phase $2 \mathrm{a}$ clinical trial. EBioMedicine. 2018;33:282-8. https://doi.org/10. 1016/j.ebiom.2018.06.022.

113. Dell'Atti L. Tadalafil once daily and intralesional verapamil injection: a new therapeutic direction in Peyronie's disease. Urol Ann. 2015;7(3):345-9. https://doi.org/10.4103/0974-7796.152048.

114. Seidai S, Shintaro S, Shinya H, Shun M, Shuichi A, Hiroyasu O, et al. Anti-fibrotic efficacy of nintedanib in pulmonary fibrosis via the inhibition of fibrocyte activity. Respir Res. 2017;1:1. https:// doi.org/10.1186/s12931-017-0654-2.

115. Beasley R, Holliday M, Reddel HK, Braithwaite I, Ebmeier S, Hancox RJ, et al. Controlled trial of budesonide-formoterol as needed for mild asthma. N Engl J Med. 2019;380(21):2020-30. https://doi.org/10.1056/NEJMoa1901963.

116. Michalik M, Wojcik-Pszczola K, Paw M, Wnuk D, Koczurkiewicz P, Sanak M, et al. Fibroblast-to-myofibroblast transition in bronchial asthma. Cell Mol Life Sci. 2018;75: 3943-61. https://doi.org/10.1007/s00018-018-2899-4.

117. Genetic Engineering, Biotechnology News. Renovo stock plummets $74 \%$ as lead scar reducing candidate fails in EU phase III trial. Mary Anne Liebert, Inc. 2011. https://www.genengnews. com/topics/drug-discovery/renovo-stock-plummets-74-as-leadscar-reducing-candidate-fails-in-eu-phase-iii-trial/. Accessed on 10/9/2020.

118. Korman B. Evolving insights into the cellular and molecular pathogenesis of fibrosis in systemic sclerosis. Transl Res. 2019;209: 77-89.

119. Bielefeld KA, Amini-Nik S, Alman BA. Cutaneous wound healing: recruiting developmental pathways for regeneration. Cell Mol Life Sci. 2013;70:2059-81. https://doi.org/10.1007/ s00018-012-1152-9. 
120. Yang Y, Jiang HY, Shi Y, He JL, Su S, Chen Z. Chinese herbal medicine for carriers of the hepatitis B virus: an updated systematic review and meta-analysis. Pharmazie. 2014;69(10):723-730.

121. Shin HS, Grgic I, Chandraker A. Novel targets of immunosuppression in transplantation. Clin Lab Med. 2019;39(1):157-69. https:// doi.org/10.1016/j.cll.2018.10.008.

122. Darakhshan S, Pour AB. Tranilast: a review of its therapeutic applications. Pharmacol Res. 2015;91:15-28. https://doi.org/10. 1016/j.phrs.2014.10.009.

123. Massagué J. A very private TGF- $\beta$ receptor embrace. Mol Cell. 2008;29(2):149-50. https://doi.org/10.1016/j.molcel.2008.01. 006.

124. Soreide E, Murad MH, Denbeigh JM, Lewallen EA, Dudakovic A, Nordsletten L, et al. Treatment of Dupuytren's contracture: a systematic review. Bone Joint J. 2018;100-B(9):1138-45. https:// doi.org/10.1302/0301-620X.100B9.BJJ-2017-1194.R2.
125. Pendleton CM, Wang R. Peyronie's disease: current therapy. Transl Androl Urol. 2013;2(1):15-23. https://doi.org/10.3978/j. issn.2223-4683.2013.03.01.

126. Gokce A, Wang JC, Powers MK, Hellstrom WJ. Current and emerging treatment options for Peyronie's disease. Res Rep Urol. 2013;5:17.

127. Roth M, Eickelberg O, Kohler E, Erne P, Block LH. Ca2+ channel blockers modulate metabolism of collagens within the extracellular matrix. PNAS. 1996;93(11):5478-82.

128. Dinarello CA. Interleukin-1 in the pathogenesis and treatment of inflammatory diseases. Blood. 2011;117(14):3720-3732.

Publisher's Note Springer Nature remains neutral with regard to jurisdictional claims in published maps and institutional affiliations. 